\title{
3. Die Deutschen in der UdSSR in der Sicht des nationalsozialistischen Deutschlands 1933 bis 1941
}

Mit der Machtergreifung der Nationalsozialisten avancierte ein Parteiprogramm zur staatspolitischen Maxime, das als erstes Ziel der Außenpolitik die Vereinigung aller Deutschen im Großdeutschen Reich auf der Basis des Selbstbestimmungsrechts anstrebte. Bei diesem Anspruch ging es zunächst um die deutschen Bewohner jener Gebiete, die nach dem Zusammenbruch der Mittelmächte bei der durch die Verträge von Versailles und St. Germain fixierten Staatenneuordnung den europäischen Nachbarn zugefallen waren. Neun Millionen Deutsche, die seither das Schicksal der nationalen Minderheiten in den angrenzenden Staaten teilten, sollten - wie der neue Reichskanzler Adolf Hitler in seiner Reichstagsrede vom 23. März 1933 betonte von nun an unter dem vollen Schutz des Deutschen Reiches stehen. Hinter diesen Beteuerungen stand die Idee von der völkischen Einheit, die Hitler bereits in Mein Kampf hinreichend klar ausgeführt und belegt hatte: die Vorstellung, daß „gleiches Blut zum gleichen Reich" geführt werden müsse, und daß dem deutschen Volk keinerlei Recht auf Kolonialpolitik zustehe, solange nicht „die Grenzen des deutschen Reiches den letzten Deutschen" einschlössen.

Die Erhebung der völkischen Einheitsidee auf das staatspolitische Panier ließ eine Fülle neuer Organisationen und Institutionen aus dem Boden sprießen, die sich alle der Rettung der Brüder und Volksgenossen vor den Toren des Reiches annehmen wollten. Hier spielten auch die in deutscher Emigration lebenden Deutschrussen eine namhafte Rolle.

Der Streit um das „Rußlanddeutschtum“ in den neuen Ämtern 1933 bis 1939

Die neuen politischen und ideologischen Perspektiven, die das nationalsozialistische Deutschland eröffnete, nährten in den ehemaligen deutschrussischen Kreisen wie bei anderen Emigrantengruppen des früheren Zarenreiches die Hoffnung, durch aktive Mitarbeit eine Wende des Schicksals der eigenen Volksgruppe in der UdSSR anbahnen zu können ${ }^{1}$. Auch wenn sie selbst zunächst kein explizit nationalsozialistisches Programm parat hatten, bot ihnen die völkische Einigungsidee doch Aussicht auf eine

1 Vgl. hierzu: Just, A., Rußland in Europa, Stuttgart 1949; Laqueur, Deutschland, S. 187-236; Williams, Culture, „The Third Kingdom“, S.331-62. Zur Literatur über die Deutschen in der Sowjetunion in dieser Zeit vgl.: Materialien zur Geschichte des Volksdeutschtums in der UdSSR. Während der Zeit nach dem 1. Weltkrieg, insbesondere während der Jahre 1933-41. Ausgewählt und zusammengestellt von O.Böss, München 1960. 
aktive deutsche Rußlandpolitik, die eine direkte Einflußnahme auf die Situation der Deutschen in der UdSSR erlauben konnte. Diejenigen, die - durch die Nichteinmischungspolitik des Weimarer Deutschland enttäuscht und entmutigt - ins Ausland gegangen waren, kamen nun wieder nach Deutschland; Karl Stumpp und Eduard Krause brachen ihre Lehrtätigkeit an deutschen Schulen in Rumänien ab, um sich dem Stab des Deutschen Auslandsinstituts anzuschließen, Georg Leibbrandt kehrte aus den Vereinigten Staaten zurück. In Berlin umgab sich Alfred Rosenberg als Leiter des Außenpolitischen Amtes (APA) der NSDAP (das dem Stellvertreter des Führers, Rudolf Heß, unterstand) mit einem Stab von ehemaligen Deutschrussen und Deutschbalten. Die höchste Position unter ihnen nahm ab 1.10. 1933 Leibbrandt ein, er wurde Leiter der Abteilung Osten (ab 1939: Amt Osten) des APA. Nach der Bildung des Reichsministeriums für die besetzten Ostgebiete unter Rosenberg (1941) übernahm Leibbrandt dort die Hauptabteilung I, Politische Abteilung. Leibbrandt war zugleich Kontaktmann zu den Ukrainern und uḱrainischen Nationalisten und der Spezialist des Hauses für die Deutschen in der Sowjetunion. Als politischer Berater Rosenbergs und Stabsleiter im APA fungierte dessen früherer Konphilister Arno Schickedanz. Zur Abteilung Osten gehörten neben Leibbrandt der junge deutschbaltische Turkologe Gerhard von Mende, ein Spezialist für die Fragen der kaukasischen und Turkvölker der UdSSR, der Deutschbalte Harald Siewert, Propagandist der Verschwörungstheorie gegen das deutsche Volk, und N.Talberg, russischer Monarchist und Korrespondent der Pariser Emigrantenzeitschrift Vozroždenie.

Der Sektor „Rußlanddeutschtum “2 fiel vor allem in die Kompetenz von Leibbrandt. Von ihm gingen die wichtigsten Initiativen zur Organisierung und Neuordnung des Rußlanddeutschtums in der Emigration aus. Rosenberg billigte Leibbrandts Aktivitäten unbesehen und ließ ihm bei der Verfolgung seiner Ziele weitesten Spielraum.

Einen ersten Erfolg konnte Leibbrandt 1935 verbuchen: den Zusammenschluß aller in deutscher Emigration lebenden Gruppen und Verbände von Deutschen aus Rußland in der Dachorganisation „Verband der Deutschen aus Rußland e.V.“ (VDR) unter der nominellen Leitung von Adolf Frasch. Dies war eine nicht unbeträchtliche Leistung, denn wie jede andere russische Emigrantengruppe waren auch die Deutschen aus Rußland in zahlreiche, untereinander zerstrittene Verbände aufgeteilt. Das Spektrum reichte von landsmannschaftlichen Hilfsorganisationen (wie dem Verband der Schwarzmeerkolonisten, gegründet 1920) über Verbände mit kulturell-nationaler Inspiration (z.B. Johannes Schleunings Verband der Wolgadeutschen, gegründet 1918, und Theodor Hummels Verband der Kaukasusdeutschen, gegründet 1918) zu

2 Eine offizielle Sprachregelung legte 1935 in den mit deutschen Volkstumsfragen betrauten Institutionen fest, daß die Deutschen aus und in Rußland als „Rußlanddeutsche“ bezeichnet werden sollen. Gleicherweise sollten auch die gebietlichen Untergruppen, etwa die Deutschen aus Wolhynien, aus dem Schwarzmeer- und Wolgagebiet von nun an „Wolhynien-“, „Schwarzmeer-" und „Wolgadeutsche" genannt werden. Diese Sprachregelung ging auf das alldeutsche Gedankengut zurück: Das deutsche Volkstum in aller Welt sei unabhängig von dem Orte, an dem es wohne, wesensgleich, die örtlichen Attribute folglich austauschbar und für die „Sammlung des Deutschtums" in aller Welt unwesentlich. 
national bis nationalistisch inspirierten Verbänden (so Adolf Eichlers Verband der Deutschen aus Kongreßpolen, gegründet 1919, oder der Arbeitsgemeinschaft der Deutschen aus Rußland und Polen, deren Vorsitz seit 1925 Carlo von Kügelgen innehatte). Nur wenige dieser Vereinigungen, wie etwa die Gruppen von Eichler und Kügelgen, hatten sich bis dahin zu einem irgendwie gearteten Paktieren mit dem $\mathrm{Na-}$ tionalsozialismus hinreißen lassen. - Als Verband von früheren Auslandsdeutschen wurde der VDR lose dem Volksbund für das Deutschtum im Ausland angegliedert. Da dieser in die Kompetenz des Reichspropagandaministers fiel, mußte Leibbrandt notgedrungen den Propagandaminister an der Gründung des VDR beteiligen. Um dessen Einfluß gering zu halten, versuchte er zugleich, das Auswärtige Amt einzuschalten. Als Ziel der Verbandsgründung sah es Leibbrandt an, zunächst eine gewisse Kontrolle über alle in Deutschland lebenden Deutschrussen zu gewinnen und sie anschließend durch intensive Verbandsarbeit auf ihre zukünftigen politischen Aufgaben vorzubereiten ${ }^{3}$. Zur gleichen Zeit (Oktober 1935) arbeitete die Abteilung Osten des APA der NSDAP bereits ein Ausbildungsprogramm für rußlanddeutsche Frauen aus: Aus den Kreisen der deutschrussischen Emigranten sollten geeignete Frauen ausgewählt und für eine propagandistische Tätigkeit geschult werden ${ }^{4} .1937$ war die Verbandsarbeit soweit gediehen, daß Leibbrandt die Registrierung aller Deutschen aus Rußland durch den VDR vornehmen lassen konnte. In seiner Aufforderung an Stabsleiter Schickedanz, der die Zustimmung von Heydrich als dem Chef der Sicherheitspolizei zu dieser Registrierung einholen sollte, unterstrich Leibbrandt das „politische Interesse ..., diese Leute zu erfassen, die sich in den verschiedenen Gegenden der Sowjetunion auskennen, sowie die Sprache beherrschen" ${ }^{\text {. }}$.

Ein zweites wichtiges Ziel sah Leibbrandt darin, die Unklarheit zu beseitigen, die seiner Meinung nach in den Kreisen nationalsozialistischer Amtsträger über Bestand, Wert und Bedeutung des Rußlanddeutschtums herrschte. Zwar hatten Schriften belletristisch-propagandistischer Literatur, wie etwa die Bücher von Edwin E. Dwinger, Josef Ponten und Abraham Kroeker mit ihren alarmierenden Mitteilungen über das Schicksal der deutschen Volksgruppe im Sowjetstaat, die öffentliche Meinung in Deutschland in einem für diese Arbeit sehr vorteilhaften Sinne vorgeprägt. Doch ließen es nach Leibbrandts Ansicht die einflußreichen Männer in Deutschland noch immer an Interesse für die Rußlanddeutschen fehlen. Sie unterschätzten, so glaubte er, die „volksbiologische Kraft" dieser Volksgruppe, die sich dank ihrer hohen „natürlichen Reproduktionswerte" und ihrer äußersten Anspruchslosigkeit auch nach schweren Schicksalsprüfungen immer wieder als ein wertvolles kolonisatorisches Element des Ostens erwiesen habe. In praktischer und politischer Hinsicht sah er es deshalb als verfehlt und der „nationalsozialistischen Weltanschauung “ widersprechend an, wenn

${ }^{3}$ Aktennotiz, APA, NSDAP, Abt. Osten, 11.Dez. 1935, GR T 81, R 11, und EAP 250-d-18-05/ 4-15.

${ }^{4}$ APA, NSDAP, Abt. Osten, Aktennotiz von Dürksen über ein Treffen zur Vorbereitung des Ausbildungsprogramms, EAP 250-d-18-05/4.

5 APA, NSDAP, Abt. Osten, Brief Leibbrandts an Stabsleiter Schickedanz, im Hause, vom 5. 2. 1937, EAP 250-d-18-05/5. 
die Mehrheit der hohen Amtsträger das Rußlanddeutschtum als „bolschewisiert“ und „für das Deutschtum verloren" hielt ${ }^{6}$. Mit aller Kraft setzte er sich daher im Rahmen seiner Tätigkeit in der Abteilung Osten und als Leiter der Abteilung zur Bekämpfung des Bolschewismus im APA der NSDAP dafür ein, die Überzeugung von der biologischen Kraft und ideologischen Unversehrtheit der Deutschen in Rußland sowie von ihrer Bedeutung für die zukünftigen deutschen „Aufgaben“ im Osten zu verbreiten. Ihren ersten und nächsten Rivalen in den Fragen des Rußlanddeutschtums besaß die Abteilung Osten des APA der NSDAP in Joseph Goebbels' Reichsministerium für Volksaufklärung und Propaganda (RMVP). Auch Goebbels hatte den Nutzen deutschrussischer Emigranten für die Propagandaarbeit frühzeitig erkannt. Er hatte den Volksbund für das Deutschtum im Ausland der Abteilung II (Propaganda-Abteilung) seines Ministeriums unterstellt; damit fiel auch der dem VDA angegliederte Verband der Deutschen aus Rußland e.V. der Form nach in seine Kompetenz'. Wichtiger als diese wenig wirksame, da kurze Zeit später von der SS in der Praxis nichtig gemachte Unterstellung war die Arbeit des Gesamtverbandes Deutscher Antikommunistischer Vereinigungen (kurz: Antikomintern), den Goebbels im Winter 1933/34 unter der Ägide seines Ministeriums geschaffen hatte. Dabei hatte er das Abhängigkeitsverhältnis zu einem „Staatsgeheimnis“ erklärt - in der Öffentlichkeit erschien die Antikomintern „zum Zwecke der Tarnung“ als unabhängige Organisation ${ }^{8}$. Aus diesem Grunde war die Antikomintern formal in zwei dem Anschein nach getrennt voneinander bestehende Organe aufgeteilt: Die Abteilung Antibolschewismus (Abteilung II/4 des RMVP) unter Dr. E. Taubert und die nach außen autonome publizistisch-wissenschaftliche Organisation Antikomintern unter der Leitung von Adolf Ehrt. Die wirkliche Leitung hatte der ideologische Chef der Antikomintern und Goebbels-Intimus Dr. Taubert' ${ }^{9}$. Auf seine Anregung ging auch die Arbeitsteilung der beiden Organe zurück.

A.Ehrt, Lehrer an der Deutschen Hochschule für Politik in Berlin und Mennonit deutschrussischer Herkunft ${ }^{10}$, verfügte über gute Kontakte zu kirchlichen Organisationen verschiedener Konfession im In- und Ausland. Als Verfasser von Arbeiten über

6 Vgl. Empfehlungen Leibbrandts an Rosenberg für eine Rede vor dem Volksdeutschen Klub vom 29. Nov. 1939, EAP 250-d-18-05/6.

7 Vgl. den Aufsatz von V.Wagner über die Arbeit des VDA 1933-40, GR T 21, R 502, F $5265243 \mathrm{ff}$.

${ }^{8}$ Goebbels am 10.1. 1936; vgl. Laqueur, Deutschland, S. 209 ff. Zahlreiche Manuskripte und Veröffentlichungen der Antikomintern sind enthalten in: Antikomintern Collection, Hoover Library, Palo Alto, Stanford, Calif. Der nach außen hin neutrale Nibelungen-Verlag, Leipzig/Berlin, war einer der Hausverlage der Antikomintern. Unter der Führung Tauberts übernahm der VDR als Gliederung des VDA die seit den 20er Jahren in deutschrussischen Kreisen florierende Zeitschrift Deutsche Post aus dem Osten, ernannte den Mitarbeiter der Antikomintern Carlo von Kügelgen zum Herausgeber und gab der Zeitschrift ein deutlich nationalsozialistisches Gepräge.

9 Vgl. den von Taubert vor Kriegsende verfaßten Bericht: „Querschnitt durch die Tätigkeit des Arbeitsgebiets Dr. Taubert (Antibolschewismus) des RMVP bis zum 31. Dezember 1944“, Original in den Archiven des Yivo Institute for Jewish Research, New York.

10 Über Ehrt vgl. GR T 81, R 14; EAP 250-d-18-15/5. 
die russischen Mennoniten ${ }^{11}$, dessen Ansichten über das jüdisch-bolschewistische Rußland sich mit denen der Nationalsozialisten deckten, war Ehrt 1932 der NSDAP beigetreten ${ }^{12}$. Wenige Jahre später hatte er sich unter dem Druck der mit ihm zusammenarbeitenden kirchlichen Organisationen mit der Erklärung von der Partei distanziert, er könne der NSDAP außerhalb ihrer Ränge besser dienen. Gegen Ende der 30er Jahre sollte Ehrt von der politischen Bühne verschwinden.

Im Rahmen seiner Arbeit bei der Antikomintern sah es Ehrt als Hauptaufgabe an, die ideologischen Grundlagen für die bevorstehende Konfrontation mit dem Sowjetstaat zu legen - eine Orientierung, die sich von der auf Erzeugung von $\mathrm{Haß}$ und Angst ausgerichteten Tätigkeit anderer NS-Organe lediglich in Nuancen unterschied. Seine Kenntnis des Sowjetsystems zwang ihn zu der Annahme, daß es das nationalsozialistische Deutschland bei der Sowjetführung mit einem ernstzunehmenden ideologischen Gegner zu tun habe, dessen Anspruch auf Herrschaft in Rußland und Ausbreitung seiner Macht auf Deutschland nur durch eine fundierte wissenschaftlich-ideologische Widerlegung und Aufdeckung der inneren Widersprüche zu brechen sei. Zu diesem Zwecke leitete der Assistent Ehrts, Hermann Greife, ab 1936 die „Säuberung“ des gesamten Apparates der Ostwissenschaft und Ostgeschichte in Deutschland ein. Den Auftakt dazu bildete Greifes Schrift „Sowjetforschung. Versuch einer nationalsozialistischen Grundlegung der Erforschung des Marxismus und der Sowjetunion "13. Opfer der Aktion wurden die traditionelle liberale bis nationalliberale deutsche Ostforschung (Otto Hoetzsch und seine Schule) und die als „liberal“ und „prosowjetisch" denunzierten Journalisten (wie der in Moskau geborene Klaus Mehnert); nach Abschluß der "Säuberung“ (1938) waren sämtliche Spitzenpositionen der deutschen Ostwissenschaft von auf das nationalsozialistische Rußlandbild fixierten Leuten ${ }^{14}$ besetzt. Sie und andere von Greife geförderte Autoren ${ }^{15}$ bemühten sich nun in ideologisch unbeholfener und weithin pseudowissenschaftlicher Diktion, den „Papierti-

11 Ehrt, A., Das Mennonitentum in Rußland von seiner Einwanderung bis zur Gegenwart, Berlin/ Leipzig 1932.

12 Ehrt, A., Entfesselung der Unterwelt, Berlin/Leipzig 1932; ders., Bewaffneter Aufstand, Berlin 1933; ders., Terror: Die Blutchronik des Marxismus in Deutschland, Berlin/Leipzig 1934.

13 Berlin/Leipzig: Nibelungen 1936, mit einem Vorwort von Dr. A. Ehrt. Vgl. ferner die Schriften Greifes: Die Klassenkampfpolitik der Sowjetregierung, Berlin/Leipzig 1937; Ist die Entwicklung der Sowjetunion zum nationalen Staat möglich? Berlin 1939, und zahlreiche Flugschriften.

$14 \mathrm{Zu}$ ihnen gehörten R. Maurach (Russische Judenpolitik 1939, Aufsätze über die russischen Juden in: Volk und Reich, November 1939, S.809-19; und in Der Weltkampf, November 1939, S. 469-75) und Peter-Heinz Seraphim (Das Judentum im osteuropäischen Raum, Essen 1938; Die Bedeutung des Judentums in Südosteuropa, Berlin 1941; Das Judentum: Seine Rolle und Bedeutung in Vergangenheit und Gegenwart, München 1942; Bevölkerungs- und wirtschaftspolitische Probleme einer europäischen Gesamtlösung der Judenfrage, München 1943). Die erste gemeinsame Veröffentlichung der neuen Ostexpertengeneration war der von Bolko von Richthofen herausgegebene Sammelband: Bolschewistische Wissenschaft und Kulturpolitik, Königsberg 1938.

15 U. a. Bockhoff, E.H., Völkerrecht gegen Bolschewismus, Berlin 1938; Laubenheimer, A. (Hrsg.), Und du siehst die Sowjets richtig ... Berichte von deutschen und ausländischen Spezialisten aus der Sowjetunion, Berlin/Leipzig 1937². 
ger" 16 Sowjetmacht zur Strecke zu bringen. „Zwingend“ wurde die Beweisführung ihrer Schriften erst dort, wo es um die menschlich-sozialen Fragen, etwa die an dem russischen und deutschrussischen Bauerntum begangenen Greuel, ging. Doch auf diesem Sektor lief ihnen das von Tauberts Propagandaabteilung herausgebrachte Schrifttum eindeutig den Rang ab.

Taubert legte Wert darauf, Autoren mit persönlichen Erfahrungen (unter ihnen Überläufer der ideologischen Front zwischen dem Sozialismus sowjetischer Prägung und dem deutschen Nationalsozialismus mit dem ihnen eigenen $\mathrm{Maß}$ an $\mathrm{Haß}$ der Getäuschten und Hintergangenen) $\mathrm{zu}$ Wort kommen zu lassen. Solche Autoren waren die in den dreißiger Jahren in der Sowjetunion und zum Teil danach auch kurzzeitig in Deutschland inhaftierten Deutschen Rudolf Kommoss ${ }^{17}$ und Karl J.LoewAlbrecht. Albrecht, Verfasser des Buches Der verratene Sozialismus, war in den späten zwanziger und frühen dreißiger Jahren stellvertretender Volkskommissar für Forstwesen gewesen, hatte Stalin und Molotow persönlich gekannt und war nach seiner Haft in der UdSSR an das nationalsozialistische Deutschland ausgeliefert worden. Im Gegensatz zu dem Theoretiker Ehrt war dem ambitiösen Taktiker Taubert sehr an praktischer politischer Einflußnahme gelegen. Taubert hat wiederholt darauf hingewiesen, daß die deutsche Außenpolitik in der Anfangsphase des Dritten Reiches nicht im Auswärtigen Amt, sondern im Propagandaministerium, und hier vor allem in der Antikominternabteilung, gemacht worden sei. Dies traf in hohem Maße auf die ersten außenpolitischen Schritte zu, die das nationalsozialistische Deutschland in Hinblick auf das Rußlanddeutschtum, die hungernden deutschen Bauern in der UdSSR, unternahm.

1933/34 erreichte die Hungersnot in Rußland ihr schlimmstes Ausmaß. Wie zu Beginn der zwanziger Jahre, waren es auch in diesen Jahren vor allem kirchliche und humanitäre Organisationen, die den „Brüdern in Not“ in der Sowjetunion zu Hilfe zu kommen suchten ${ }^{18}$. Die Antikomintern nutzte die faktisch bestehende Not der zwangskollektivierten deutschen Bauern sowie die bereits im Gange befindliche weltweite Protest- und Hilfsaktion aus, um den antisowjetischen Zielen des nationalsozialistischen Deutschland in der Weltöffentlichkeit Glaubwürdigkeit zu verschaffen. Zunächst trat der in internationalen kirchlichen Organisationen als verläßlicher Kenner der Lage eingeführte Ehrt mit einer Schrift an die Öffentlichkeit ${ }^{19}$. Dann wurde Ewald Ammende, ein mit Rosenberg bekannter Deutschbalte aus Reval (Tallin) und

\footnotetext{
16 Nach dem wohlgewählten Ausdruck von Just (Rußland, S. 40).

17 Juden machen Weltpolitik, Berlin o.J.; Juden hinter Stalin, Berlin/Leipzig 1938.

18 Vgl. Brüder in Not! Dokumente des Massentodes und der Verfolgung deutscher Glaubens- und Volksgenossen im Reich des Bolschewismus. Herausgegeben von der Informationsabteilung des Evangelischen Pressverbandes für Deutschland. Berlin-Steglitz 1933; Geissler, B., Bruhns, O., Vom Deutschtum in Rußland, Leipzig: Centralvorstand des Evangelischen Vereins der GustavAdolf-Stiftung 1934; Deutsche Brüder schreiben aus russischer Hungersnot. Mit einem Geleitwort von Ludwig Berg, Geilenkirchen (Rheinland) 1935; Rußland, o Rußland! Stuttgart 1934.

19 Brüder in Not! Dokumente der Hungersnot unter den deutschen Volksgenossen in Rußland. Zusammengestellt von Adolf Ehrt, Berlin-Steglitz, um 1933.
} 
aktiver „Auslandsdeutscher", Verfasser der Schrift Muß Rußland bungern?, von der Antikominternabteilung Tauberts für die Ziele des Propagandaministeriums gewonnen. Als Generalsekretär des Kongresses Europäischer Nationalitäten hatte Ammende ein entscheidendes Wort in Fragen der Hungerhilfe mitzusprechen. Wenn es Taubert - nach eigenen Aussagen - gelang, über seinen verlängerten Arm in den kirchlichen Institutionen Ehrt, die kirchlichen Hilfswerke in Deutschland zu Marionetten des Reichspropagandaministeriums zu machen, so vermochte er mit Hilfe Ammendes die europäische Öffentlichkeit, u.a. den Erzbischof von Canterbury, von der Berechtigung des Begehrens des nationalsozialistischen Deutschland zu überzeugen. Es ging, wie Tauberts Aufzeichnungen nur allzu klar belegen, nicht um die Änderung des Schicksals der in der Sowjetunion verhungernden deutschen Bauern, sondern um den Durchbruch in der außenpolitischen Aufwertung des NS-Staates mit Hilfe von Täuschung und Irreführung der Weltöffentlichkeit.

Auch die Thematik der Parteitage der NSDAP, wichtiger Indikator außenpolitischer Kursänderungen, ist nach Angaben Tauberts von der Antikominternabteilung des Propagandaministeriums wesentlich mitbestimmt worden ${ }^{20}$. So habe die Antikomintern Hitlers scharfe antisowjetische Wende um die Mitte der 30er Jahre, wie sie im Thema des NSDAP-Parteitages von 1935, „Die entscheidende Richtunggebung der deutschen Politik“, zum Ausdruck kam, mitformuliert. Die Ausführungen des Parteitags von 1936 sind vermutlich ebenfalls zum großen Teil in den Räumen der Antikominternabteilung erarbeitet worden ${ }^{21}$. Gesamttenor der Reden war die rassischideologische Unversöhnlichkeit, der notwendige und bevorstehende Kampf zwischen dem russisch-jüdisch-bolschewistischen Marxismus und dem deutschen Volkstum. In der Formulierung Goebbels: der russisch-jüdische Bolschewismus sei die „Organisation der gestaltlosen Gegenrasse“, „der niedrigsten Instinkte eines Volkes zur Vernichtung aller hochwertigen rassischen Elemente" ${ }^{\prime 22}$. Es waren, wie sich auch aus den anderen Ausführungen zum Agrarterror in der Sowjetunion ergab, vor allem die wertvollen Elemente des deutschen „Volkstums“ in der UdSSR, die nun als vorrangige Opfer der „jüdischen Gegenrasse“ in GPU-Kellern und Zwangsarbeitslagern zu Tode gemartert würden. Hitler, dem die Schlußrede auf diesem Parteitag zufiel, hielt sich merklich von den auf haßerfüllte Konfrontationspolitik ausgerichteten Ausführungen seiner Vorredner zurück: Er umging die Fragen des Stalinschen Terrors und besonders des Schicksals der deutschen Volksgruppe in der UdSSR und erhob statt dessen den Anspruch, daß die wahre Revolution in Deutschland stattfinde, der wahre sozialistische Arbeiterstaat in Deutschland entstehe; er selbst sei schließlich noch vor wenigen Jahren Arbeiter gewesen! ... Ein taktisch-ideologischer Rückzug, der die Möglichkeit eines Paktierens mit dem Sowjetstaat zum Zwecke des Zeitgewinns für Kriegsvorbereitungen offenließ.

Die Spannungen zwischen Tauberts Antikominternabteilung im RMVP und Leibbrandts Abteilung Osten des APA der NSDAP, die zeitweilig sogar zur Auferlegung eines Redeverbots zwischen den Mitarbeitern der beiden Abteilungen durch Goeb-

${ }^{20}$ Vgl. Taubert, Querschnitt, und dazu Laqueur, Deutschland, S. $225 \mathrm{ff}$.

${ }^{21}$ Vgl. Parteitag der NSDAP 1936, Reden. 22 Ebenda, S. 17. 
bels führten, verloren ab 1936 zunehmend dadurch an Bedeutung, daß sich als dritter Rivale Himmlers SS den Zugriff auf den Bereich Sowjetunion, vor allem auf die Volkstumsangelegenheiten im Osten, zu sichern begann ${ }^{23}$. Eine Ursache für die sich anbahnende Ablösung der Kompetenzen war neben dem rücksichtslosen Machtdrang der Männer der SS der in SS- und Führer-Kreisen weitverbreitete Unwillen, wenn nicht $\mathrm{Haß}$, gegenüber deutschrussischen und besonders deutschbaltischen Elementen im Machtapparat. Soziale Unterlegenheitsgefühle dürften ein auslösender Faktor dieser Einstellung gewesen sein. Aber auch das Empfinden, daß der eher konservative Ehrenkodex des Deutschbalten und Deutschrussen, so sehr er auch durch Antisemitismus und Slawenhaß angegriffen sein mochte, sich kaum jemals glaubwürdig und total auf die Unmoral des nationalsozialistischen „Herrenmenschen“ würde umpolen lassen, trug zu einer gewissen Distanz mit allen Anzeichen von Hohn, Spott und Verachtung gegenüber diesen ehemals osteuropäischen Volksdeutschen bei. Hitler selbst glaubte bemerkt zu haben, daß Deutsche, die lange Zeit in Rußland gelebt haben, niemals wieder echte Deutsche werden könnten; die Faszination der großen Räume habe von ihnen Besitz ergriffen. Und er sprach offen aus, daß ein Mann wie Rosenberg nur deshalb ein Russenhasser geworden sei, weil ihm die Russen nicht ermöglicht hätten, einer der ihren zu werden ${ }^{24}$.

Diese Einstellung, begünstigt durch das bereitstehende Potential an Neid gegenüber den führenden Schichten wie dem baltischen Adel, fand in breiten, politisch mobilisierten Unterschichten ein lebhaftes Echo. So hatte schon 1933 ein gewisser Dr. Müller aus Chemnitz, Parteiveteran und -aktivist, in einer Denkschrift an das Auswärtige Amt davor gewarnt, russische Adlige und insbesondere Deutschbalten in der deutschen Emigration mit irgendwelchen Funktionen in Hinblick auf Rußland auszustatten; nichts sei schlimmer für das deutsche Volk, als diese in Rußland meistgehaßten Leute mit Amt und Würden zu versehen ${ }^{25}$. Eine vergleichbare Einstellung war auch für die Männer in den neugegründeten nationalsozialistischen Stäben und Organen weithin charakteristisch. Solange Deutschbalten und Deutschrussen als Experten, ihre Kenntnisse zur Vorbereitung der deutschen Unternehmen im Osten benötigt wurden, gewährte man ihnen eine gewisse, wohlbewachte Einflußsphäre. Als ihre Zuliefererdienste nach Beginn des Zweiten Weltkrieges und besonders im Fortgang des Rußlandfeldzuges in zunehmendem Maße überflüssig und unerwünscht wurden, neutralisierte man sie kurzerhand durch Kompetenzbeschneidung oder Einziehung zum Wehrdienst.

Der zuständige Mann des selbst an Volkstumsfragen und Ostsiedlung unter alldeutschem Vorzeichen in hohem Maße interessierten Reichsführers SS ${ }^{26}$ war seit

${ }^{23}$ Das zwischen Abteilung Osten und Antikomintern bestehende Redeverbot wurde charakteristischerweise 1936, als sich der dritte Rivale regte, aufgehoben; vgl. Laqueur, Deutschland, S. 213.

${ }^{24}$ Rauschning, H., The Voice of Destruction, New York 1940, S.132; dt.: Gespräche mit Hitler, Zürich $1940^{2}$.

${ }^{25}$ AA IV Rußland, Pol.2, Band 19 (Mai-August 1933), S. 408; vgl. auch den Bericht der Bayrischen Gestapo vom 11. Mai 1934, Abschrift im Institut für Zeitgeschichte, München (IfZ).

26 Vgl. Ackermann, J., Heinrich Himmler als Ideologe, Göttingen 1970, S. 198 ff. 
1937 Himmlers enger Mitarbeiter, SS- und Parteiveteran Werner Lorenz ${ }^{27}$, Leiter der Volksdeutschen Mittelstelle (Vomi). Als SS-Agentur, die zunächst dem Auswärtigen Amt angegliedert war, löste die Vomi am 1.1. 1937 das von-Kursell-Amt ab. Ihre Funktion bestand offiziell zunächst in der Kontaktaufnahme zu Deutschen, die im Ausland lebten und nicht deutsche Staatsbürger waren, daher ihre dem Anschein nach berechtigte Angliederung an das Auswärtige Amt. Bei Kriegsbeginn wurde diese Form von Tarnung für überflüssig befunden, und die Dienststelle offiziell zum SSHauptamt Volksdeutsche Mittelstelle aufgestuft.

Lorenz' Interesse am Auslandsdeutschtum mußte ihn in Konflikt mit bereits bestehenden Institutionen bringen, vor allem mit der Auslandsorganisation (A.O.) der NSDAP unter der Leitung von E.W.Bohle, mit dem dem Reichsministerium für Volksaufklärung und Propaganda angegliederten VDA (einschließlich des ihm zugehörigen VDR, der noch immer in seinem Gründer Leibbrandt, Leiter der Abteilung Osten des APA der NSDAP, einen Patron besaß) und mit dem Deutschen Auslandsinstitut Stuttgart (DAI). Gestützt auf den allmächtigen Himmler, verstand es Lorenz aufgrund seiner Manövrierfähigkeit und Herrschsucht, in wenigen Monaten den gordischen Knoten ineinander übergreifender Kompetenzen dadurch zu lösen, daß er alle wichtigen Funktionen in seiner Hand zusammenfaßte und sich zum „obersten Befehlshaber für alle volksdeutschen Angelegenheiten“" ernannte ${ }^{28}$.

Die Kompetenzabgrenzung zwischen Lorenz und Bohle war schnell durch eine interne Einigung erreicht: Bohle mußte seinen Arbeitsbereich von nun an auf die im Ausland wohnenden deutschen Staatsbürger („Reichsdeutsche“), vorzugsweise mit $\mathrm{Zu}$ gehörigkeit zur NSDAP, beschränken, war also für die Gewinnung und aktive Vorbereitung „fünfter Kolonnen“ im Ausland zuständig'29; Lorenz bezog in seinen Ar-

${ }^{27}$ SS-Obergruppenführer Werner Lorenz, geb. 2.10. 1891 in Grünhof, Ostpreußen (?), NSDAPEintritt 1929 (Mitgl. Nr.397994), Eintritt in die SS Januar 1931 (SS-Nr.6636), Mitglied des Preuß. Landtages 1933, Mitglied des Reichstages ab 12.11. 1933 (Wahlkreis Ostpreußen); 1934-37 Führer des SS-Oberabschnittes Nord in Altona, 1937-45 Leiter der Volksdeutschen Mittelstelle. Bevollmächtigter für außenpolitische Fragen der NSDAP im Stabe des Stellvertreters des Führers. Am 10.3. 1948 in Nürnberg als Kriegsverbrecher verurteilt; erschlich sich durch Schweige- und Verniedlichungstaktik das milde Urteil von 20 Jahren Haft. Nach 1949 Revision des Urteils durch deutsche Behörden, Anfang 1955 Haftentlassung.

${ }^{28}$ Vgl. Protokoll der Besprechung im Deutschen Auslandsinstitut Stuttgart vom 23.4. 1937, in den Materialien des Deutschen Auslandsinstituts Stuttgart (DAI) in Captured German Documents (CGD), Handschriftenabteilung der Library of Congress (DAI-LC), Container Nr. 4A, Box 348, F-144, 52-162.

${ }^{29}$ Vgl. Bohle, E.W., Affidavit, Interrogation of 22 Nov. 1945, Nuremberg Military Tribunal (NMT), State Department Special Interrogation Mission, in The National Archives, Washington D.C. (NA), Record Group 238). Office of the U.S. Chief of Counsel for War Crimes, APO 696, Evidence Division, Interrogation Branch, Interrogation Summary Nr. 2753 (Obergruppenführer Gauleiter E. W. Bohle, 10 July 1947, NA, Record Group 238). Zum Kreise der Personen in verschiedenen Ländern, die als NSDAP-Mitglieder in Bohles Kompetenz fielen, vgl.: Nazi Membership Records. Submitted by the War Department to the Subcommittee on War Mobilization of the Committee on Military Affairs. US Senate, Washington D.C. 1946. Es sei der Vollständigkeit halber bemerkt, daß die wenigen NSDAP-Mitglieder in der UdSSR ausschließlich Angestellte 
beitsbereich alle Auslandsdeutschen ein, die nicht deutsche Staatsbürger waren, u.a. die auf ca. 11 Millionen bezifferten Volksdeutschen ${ }^{30}$.

Der zweite Schritt war die Entmachtung und Übernahme der für die Volksdeutschen zuständigen Institutionen VDA und DAI. Der Vorstand des VDA hatte bereits auf die Überführung der Reichsdeutschen aus seiner Kompetenz in die Bohles 1935 mit der Niederlegung der Ämter geantwortet; nur der Bundesleiter des VDA, Dr. Hans Steinacher, hatte sein Amt vorläufig behalten. Ihm gab Lorenz im Frühjahr 1937 (nach den Worten seines Mitarbeiters in der Vomi, SS-Oberführer Behrens) „... eine letzte Möglichkeit, den V.D.A. in Ordnung zu bringen ... (Vergleich: Eine Schaufel in die Hand, mit der man sowohl sein eigenes Grab graben, wie auch den organisatorischen Neuaufbau durchführen könne). Bisherige organisatorische Maßnahmen: Abkommen mit einzelnen Gliederungen der Partei (u. a. Bohles A. O., I.F.), ... um den V.D.A. in den allgemeinen Rahmen der Partei einzuführen. " ${ }^{31}$ Steinacher bestand die ihm von Lorenz gestellte Bewährungsprobe nicht und wurde 1938 auf Führerbefehl seines Amtes enthoben ${ }^{32}$. Die interessierten Nachfolger, Bohle und Lorenz, teilten die Reste der Organisation (der VDA hatte 1938 allein in Deutschland ca. 1,5 Millionen Mitglieder) untereinander auf. Lorenz fiel mit dem Löwenanteil des VDA ein wichtiger Gewinn zu: Der seit Jahrzehnten unter den im Ausland lebenden Deutschen eingeführte VDA verzeichnete einen regen Zugang an Informationen aus vielen Ländern und verfügte über fundierte Kenntnisse des Lebens von Hunderttausenden von Deutschen im Ausland ${ }^{33}$.

Gleichzeitig mit der Übernahme des VDA nahm Lorenz die Gleichschaltung des Deutschen Auslandsinstituts Stuttgart ${ }^{34}$ vor. 1917 als Informations- und Dokumentationszentrum für die Deutschen im Ausland gegründet, war das DAI nach der Machtergreifung Hitlers durch die Ernennung Stuttgarts zur „Stadt der Auslandsdeutschen" und des Stuttgarter Bürgermeisters, des Parteiveteranen Dr.K.E.Strölin, zum Vorsitzenden des Instituts politisch aufgewertet worden ${ }^{35}$. Als erster Außenste-

(bzw. Ehefrauen von Angestellten) der Botschaft, der Konsulate und der Handelsmissionen waren. Einige von ihnen waren in Rußland geboren. Sowjetische Deutsche gehörten der NSDAP nicht an.

${ }^{30}$ Vgl. Böhm, M.H., Volkszerreißung und Minderheitennot, in: K.C.v.Loesch, M.H.Böhm (Hrsg.), Grenzdeutschland seit Versailles. Die grenz- und volkspolitischen Folgen des Friedensschlusses, Berlin 1930, S.423; zu den ca. 9,1 Millionen Grenzlanddeutschen kamen die ca. 1,4 Millionen Volksdeutschen, vgl. Shechtman, J. B., European Population Transfers, 1939-1945, New York 1946, S. 29.

31 DAI-LC, 4 A, Box 348, F-144, 52-162.

32 Steinacher, H., Verpflichtendes Erbe, Kiel 1954.

$33 \mathrm{Vgl}$. Affidavit of Bohle, Interrogation of 22 Nov. 1945, S. 14.

${ }^{34} \mathrm{Vgl}$. Smith, A.L., The Deutschtum of Nazi-Germany and the United States, The Hague 1965 (Kapitel 1: The Deutsche Auslands-Institut and the Third Reich); Ritter, E., Das Deutsche Auslandsinstitut Stuttgart. Ein Beispiel deutscher Volkstumsarbeit zwischen den Weltkriegen (Frankfurter Historische Abhandlungen), Wiesbaden 1976. Beide Autoren haben das DAI-LC-Material nicht berücksichtigt.

35 Über Aufbau und Funktion des DAI vgl. DAI, Innerdienstliche Mitteilungen, 19.8. 1941, DAILC, F-144-8393, Ordner 7. 
hender hatte Bohle den Wert des DAI erkannt und die für Reichsdeutsche zuständigen Stellen zum Vehikel seiner ambitiösen Parteiarbeit im Ausland gemacht ${ }^{36}$. In den Monaten April und Mai 1937 legte dann Lorenz in zwei Besprechungen mit dem Vorsitzenden des DAI, Dr. Strölin, und dem Präsidenten, Dr. Csaki, einem aus Rumänien gebürtigen Deutschen, den künftigen Arbeitsbereich des DAI fest ${ }^{37}$ : „Für volksdeutsche Angelegenheiten“, so vermerkte Csaki, „ist er (Lorenz, I. F.) allein zuständig und grenzt das Arbeitsgebiet auch der A.O. gegenüber scharf ab. Aus einigen weiteren Bemerkungen geht klar hervor, daß er auf dem Gebiete volksdeutscher Arbeit dem Gauleiter des A.O. keine irgendwie gearteten Zugeständnisse einräumen will. Der V.D.A. bedeutet für ihn ein Organ der Durchführung, dessen Bundesleiter auf seine Weisung hört. Er stützt den V.D.A. und identifiziert ihn mit seiner eigenen Person. Das D. A.I. erkennt er voll an und hat sich bisher nur wegen sonstiger Überbeanspruchung nicht näher damit beschäftigt. ${ }^{\text {"38 }}$

Die voreilige Hoffnung auf Anerkennung des DAI durch Lorenz verflog in der zweiten Besprechung mit Lorenz. Durch den Wunsch des zunehmend verunsicherten DAI nach „Zuständigkeitsregelung auf dem volksdeutschen Gebiete“ veranlaßt, legte Lorenz nun die Karten seiner längst vorgenommenen Planung auf den Tisch. Unter wiederholter Anerkennung der bloßen Existenz des Instituts ernannte Lorenz das DAI zu einer Zentralstelle der Erfassung des ausländischen Deutschtums, die ihre gesamte volkstumsmäßige und sippenkundliche Arbeit auf die Erfordernisse der Volksdeutschen Mittelstelle einstellen müsse. Der nachfolgende Schreckeffekt, in dem Strölin am darauffolgenden Tage versuchte, für das DAI zumindest den Status einer „Dachorganisation der Sammlung und Auswertung des auslandsdeutschen und auslandskundlichen Stoffes ${ }^{\text {"39 }} \mathrm{zu}$ sichern, verpuffte ohne Antwort.

Im Rahmen der zwischen DAI und Vomi getroffenen Vereinbarungen war auch der Aufbau einer "Sippenkundlichen Forschungsstelle für das Rußlanddeutschtum“ geplant. Die historisch-dokumentarische Grundlage dieser Stelle sollte auf Anregung des DAI die in der Hauptabteilung Wanderungsforschung und Sippenkunde des DAI geführte Zentralkartei über das Deutschtum im Ausland bilden ${ }^{40}$. Im Jahre 1938 waren darin bereits 300000 Rußlanddeutsche im In- und Ausland erfaßt, und die Volkstumsspezialisten des DAI hofften, in drei bis fünf weiteren Jahren in ihr „das gesamte Rußlanddeutschtum verkarten“ zu können ${ }^{41}$. Ziel der Zentralkartei war die „Erfassung aller lebenden Rußlanddeutschen nach Namen, Alter, Herkunft, früherem Besitz in Rußland, sowie jetzigem Beruf und Aufenthalt ... Zweck dieser karteimäßigen Bestandaufnahme ist die Vorbereitung der Wiederanbahnung von Beziehungen zu dem in Rußland verbliebenen Deutschtum, sowie überhaupt die Bereithal-

\footnotetext{
36 Vgl. Strölin, K.E., Interrogation of 31 Oct. 1945, The National Archives Collection of World War II Criminals, Record Group 238, S. 13.

37 Protokolle der Sitzungen vom 23.4. und 23.5. 1937, DAI-LC, 4 A, Box 348, F-144, 52-162.

38 Ebenda.

39 Brief K. E. Strölins an Werner Lorenz vom 24.5. 1937, DAI-LC, 4 A, Box 348.

40 Vgl. die Richtlinien der Zentralkartei, DAI-LC, F-144, 8393, Container Nr. 17.

41 Vgl. Schreiben Dr. Csakis an das OKW vom 8. Dezember 1938, ebenda.
} 
tung der Rußlanddeutschen für ihren in Zukunft etwa möglichen Einsatz in Rußland. " ${ }^{22} \mathrm{Um}$ an das umfangreiche personelle und Aktenmaterial des Verbandes der Deutschen aus Rußland heranzukommen, war dessen Fusionierung mit der Forschungsstelle vorgesehen. Damit eröffnete sich für Lorenz die Aussicht, auch den VDR unter seine Kontrolle zu bringen. Er sicherte sich deshalb sofort die Oberaufsicht über die Fusion ${ }^{43}$. A. Mergenthaler, selbst Deutscher aus Rußland und Verfasser historischer Arbeiten, überbrachte Frasch in Berlin im Auftrag des DAI die Nachricht von der geplanten Verschmelzung. Die Leitung des VDR, die sich zu Recht überrumpelt fühlte, versuchte zwar, ihre ohnehin nur dem Anschein nach bestehende relative Unabhängigkeit durch Verschleppungstaktik ${ }^{44}$ noch etwas hinzuziehen; doch schließlich gelang es den Deutschrussen des DAI Frasch davon zu überzeugen, daß die Würfel ohnedies gefallen seien, und sich der VDR durch eine Fusion mit der Forschungsstelle des DAI besserstelle als mit der bloßen Übernahme durch Lorenz. Der Vertrag zwischen DAI und VDR vom 19.7. 1938, wirksam am 1.9. 193845, legte die Grundlagen für die „Forschungsstelle für das Rußlanddeutschtum“ (FoSt Ru). Ihre Aufgabe bestand darin, „das gesamte Rußlanddeutschtum in der Welt sippenkundlich und volksbiologisch zu erfassen und alles diesbezügliche Material mit größter Beschleunigung sicherzustellen". Das Arbeitsprogramm der Forschungsstelle, zu deren Leiter Dr.Karl Stumpp ernannt wurde, umriß die politischen Ziele der Arbeit genauer:

„A. Wissenschaftliche Bestandaufnahme des Rußlanddeutschtums.

In einer Sonderkartei werden die bekannten Rußlanddeutschen erfaßt, die sich auf irgend einem Gebiet hervorgetan haben: Erzieher und Lehrer, Forschungsreisende, Märtyrer, Schriftleiter, Volkstumsführer und -Förderer.

Rußlanddeutsche im höheren militärischen Grad der russischen Armee, die heute in Deutschland sind.

B. Kartei der rußlanddeutschen Siedlungen in Rußland und Übersee ...“

Unter „Forschungsmethoden und -quellen wurden genannt:

„Zu A: 1. Von Rußlanddeutschen Pläne der Ansiedlungen und des Heimatdorfes anfertigen und die Einwohner einzeichnen lassen ...

4. Bestandaufnahme während der Besatzungszeit (d.i. der Besatzung der Ukraine durch deutsche Schutztruppen 1918, I. F.) zwecks Einbürgerung und Rückwanderung.

5. Erfassung der Rußlanddeutschen im Reich.

$\mathrm{Zu}$ B: 1. Auswertung der Karten und Kalender.

2. Festlegung sämtlicher Namen der Kolonien (amtlich, Volksnamen bei Ansiedlung und spätere Änderungen).

3. Angabe der Landmenge und Bevölkerungszahl.

42 DAI-LC, 125, Forschungsstelle Rußlanddeutschtum.

43 Vgl. Korrespondenz zwischen VDR und DAI, Juli 1938, GR T 81, R 414, F 5158937-45.

44 Note von Dr. Csaki vom 15. 2. 1938, DAI-LC, 4 A, Box 348.

${ }^{45}$ GR T 81, R 414, F $5158937 \mathrm{ff}$. 
4. Angabe des Quellenmaterials über die einzelnen Kolonien in Zeitungen, Kalendern, Büchern ..."

Zum Zwecke einer gewissen Manövrierfähigkeit zwischen den Instanzen und zur Verringerung der einseitigen Abhängigkeit von Lorenz' Vomi kontaktierte die Forschungsstelle Rußlanddeutschtum auch andere Institutionen, vor allem solche, mit denen sie früher in Verbindung gestanden hatte, so das Auswärtige Amt oder das! OKW, dem sie im Dezember 1938 ihre Dienste anbot und dabei die Bedeutung betonte, die den Rußlanddeutschen in Hinblick auf ihren zukünftigen Einsatz in Rußland zukomme ${ }^{46}$.

Mitte 1937 mußte Leibbrandt erkennen, daß W. Lorenz die deutschen Volkstumsfragen im Osten zunehmend unter die Kontrolle der SS gebracht hatte. Dies veranlaßte ihn, sich selbst um eine Ausweitung seiner Kompetenzen und Stärkung seiner Position im Rahmen der NSDAP zu bemühen. Im November $1937^{47}$ bat er Rosenberg, seine bisherigen Befugnisse als Leiter der Ostabteilung sowie Leiter der Abteilung zur Bekämpfung des Bolschewismus im Außenpolitischen Schulungsamt der NSDAP, das die weltanschauliche Schulung der NSDAP in Ostfragen durchführte, in einem „Amt Osten“ („Amt für die Fragen des Bolschewismus und des Ostens“) unter Rosenbergs Führung zusammenzufassen: „In Anbetracht der Wichtigkeit dieses Arbeitsgebietes für Ihren Aufgabenbereich erachte ich die Erweiterung der verschiedenen unter meiner Leitung stehenden Abteilungen zu einem Amte als dringend erforderlich." Da Leibbrandt überdies Rosenbergs Reden und Schriften herausgab, seine Vorträge verfaßte und in vielen weltanschaulichen Fragen detaillierte Vorarbeiten leistete, kam Rosenberg dem Wunsche Leibbrandts nach einigem Überlegen entgegen. Spätestens ab 1939 konnte Leibbrandts Amt offiziell den Namen „Amt Osten“ führen.

Durch diese Tatsache ermutigt, versuchte Leibbrandt nun auch einen Vorstoß in Hinblick auf eine gewisse Kontrolle über Lorenz' alarmierende Ämterhäufungen im Rahmen der Vomi. Dabei ging es Leibbrandt wie auch dem bald für seinen Plan gewonnenen Rosenberg darum, sich trotz der nahezu vollendeten Tatsachen noch ein gewisses Mitspracherecht über die Rußlanddeutschen zu sichern. Am 2. März 1939 richtete Rosenberg ein Schreiben an Lorenz ${ }^{48}$; er empfahl, zum Zwecke einer einheitlichen Ausrichtung der Behandlung der immer akuter werdenen Ostprobleme im Rahmen des ihm vom Führer gestellten Auftrages seinen Mitarbeiter Leibbrandt „als Berater für die Fragen des Rußlanddeutschtums in die Volksdeutsche Mittelstelle zu berufen. Pg. Dr.Leibbrandt erscheint mir durch seine Geburt, seine umfangreichen

46 Schreiben der Forschungsstelle Rußlanddeutschtum an das OKW vom 8.12. 1938, DAI-LC, Box 125. Das OKW forderte gelegentlich Auftragsarbeiten an und nahm das DAI unter Bezugnahme auf die Forschungsstelle Rußlanddeutschtum in seine Liste der Informanten aus den Reihen der Auslandsinstitutionen auf: OKW. Deutsche Auslandsinstitutionen. Für den Dienstgebrauch, 1942, S. $1 \mathrm{f}$.

47 NSDAP, APA, Abteilung Osten, Schreiben Leibbrandts an Rosenberg vom 4.11. 1937, GR T 81, $\mathrm{R} 11, \mathrm{~F} 2$.

48 NSDAP, APA, Reichsleitung, an Obergruppenführer Lorenz, Volksdeutsche Mittelstelle, GR T $81, \mathrm{R} 11, \mathrm{~F} 2 \mathrm{ff}$. 
speziellen Studien und besonders durch seine langjährige Tätigkeit auf diesem Gebiete sowohl persönlich, als auch sachlich wie kein anderer für diese Arbeit geeignet."

Die erwartete Zusage blieb aus. Lorenz war nicht willens, die nunmehr in seiner Hand konzentrierte Macht zu teilen. Damit scheiterte in dieser Aufbauphase der nationalsozialistischen Organisationen der letzte Versuch der Männer deutschbaltischer oder deutschrussischer Herkunft, einen entscheidenden Einfluß auf das Schicksal und besonders die Zukunft ihrer Volksgruppe in der Sowjetunion zu gewinnen. Die Entscheidungsgewalt lag schon jetzt in weitem Maße in den Händen der SS. Wenn es in ihren Reihen zu einem Schlagwort wurde, daß „der Osten der Schutzstaffel" gehöre" ${ }^{49}$, so galt dies a fortiori in bezug auf die Volksdeutschen in Osteuropa.

\section{Vorbereitung des „Unternehmen Barbarossa“ 1939 bis 1941}

Die unerwartete außenpolitische Wendung Hitlers, die mit dem deutsch-sowjetischen Nichtangriffspakt (Molotow-Ribbentrop-Pakt vom 23.8. 1939) einsetzte, brachte den um die Rettung ihrer Volksgruppe vor der sowjetischen Herrschaft besorgten Deutschrussen im nationalsozialistischen Machtapparat neuen Verdruß. Männer wie Georg Leibbrandt in der NSDAP, Carlo von Kügelgen in der Antikomintern, Stumpp, Krause und Quiring im Deutschen Auslandsinstitut Stuttgart sahen sich in ihren Bemühungen jäh unterbrochen. Hinzu kam, daß die Richtlinien für die propagandistische Tätigkeit gegenüber der Sowjetunion nun festlegten, daß jede Reizung des mächtigen Bündnispartners im Osten durch Hinweise auf die notleidende deutsche Volksgruppe in der UdSSR zu unterbleiben habe ${ }^{50}$. Es trat eine kurze Zeit der Ernüchterung ein, in der diese Männer den Eindruck gewannen, getäuscht und hintergangen worden zu sein. Nach anfänglichen schwächlichen Protesten und Aufklärungsversuchen ${ }^{51}$, in denen die Befürchtung laut wurde, daß nun endgültig die am Schicksal der deutschen Volksgruppe desinteressierten Kräfte in den nationalsozialistischen Ämtern die Oberhand gewonnen hatten, zogen sich die deutschrussischen Emigranten in die Stille wissenschaftlich-dokumentarischer Arbeit zurück. Bald aber

49 Ausspruch von SS-Gruppenführer Hofmann, Nbg. Dok. NO-4113.

so Vgl. H. Siewert, in: Deutsche Post aus dem Osten, 1939, Nr. 8-9, S. 2.

51 So hatte Strölin auf Hinweise von Reichsminister Schacht, eines weiteren deutschrussischen Emigranten im nationalsozialistischen Apparat, dem Reichsführer SS zwei Gutachten von Karl J.Albrecht zugeschickt: „Neue Wege der Antikomintern-Arbeit“ und „Sind die deutschen Kolonisten Rußlands für Kolonisationszwecke im neuen Grenzgebiet Ost geeignet, oder sind sie eine ständige Gefahr als ,bolschewistisch verseuchte Elemente‘?", mit Anschreiben vom 3. November 1939. Strölins Empfehlungen liefen darauf hinaus, dem Kenner der Materie Albrecht und seinen Aussagen über die unbegrenzte Einsatzfähigkeit der gegen „bolschewistische Verseuchung“ immunen deutschen Kolonisten große Aufmerksamkeit zukommen zu lassen. Himmler antwortete Strölin am 20. November, daß er die Vorschläge für eine verstärkte Antikomintern-Arbeit für undurchführbar halte, und ließ die implizite Frage nach dem Einsatz der Deutschen aus der Sowjetunion unbeantwortet; vgl. GR T 175, R 37-8, F 2547306 ff., 2547482-95, Pers. Stab RFSS, Himmler File 242, EAP VIII-161-b-12/91. 
sollte ihnen die Fülle neuer Aufträge aus den verschiedenen Ressorts zeigen, daß dies eine Ruhe vor dem Sturm war und ihnen auf ihrem jeweiligen Fachgebiet durchaus die Möglichkeit zu aktiver Mitarbeit bei der Vorbereitung einer Auseinandersetzung mit der UdSSR gegeben war. Die lebhafte publizistische Produktion dieser Jahre über Geschichte und Gegenwart des Rußlanddeutschtums unterstrich dessen Wert für die zukünftige deutsche Politik in Osteuropa ${ }^{52}$.

Der Molotow-Ribbentrop-Pakt und die an ihn gekoppelten deutsch-sowjetischen Umsiedlungsverträge, welche die Aussiedlung der deutschen Volksgruppen aus den in die sowjetische Interessensphäre fallenden Teilen Ostmitteleuropas regelten, weckten in deutschrussischen Kreisen in Deutschland allerdings auch ein bestimmtes positives Interesse. Eine Flut von Briefen und Bittgesuchen sprach sich für die Einbeziehung der in der Sowjetunion verbliebenen Deutschen in diese Verträge aus. Befragungen von ca. 3400 Rückkehrern aus Rußland (vorwiegend nach der Tuchatschewski-Affäre ausgewiesene Reichsdeutsche) durch die Leitstellen der Gestapo hatten ergeben, daß auch unter den Deutschen in verschiedenen Gebieten der UdSSR Traum und Hoffnung umgingen, Deutschland werde sie aus dem „Kerker Sowjetrußland“ befreien $^{53}$. Die deutschrussischen Amtsträger griffen diese Fragestellung im Rahmen ihrer begrenzten Kompetenzen und Möglichkeiten auf und versuchten, auf entscheidende Stellen Einfluß zu nehmen.

Das Auswärtige Amt sah sich veranlaßt, eine Denkschrift auszuarbeiten, in der die Möglichkeit einer Umsiedlung der Deutschen aus dem sog. sowjetischen Kernland, den „altsowjetischen“ Gebieten, einer eingehenden Betrachtung unterzogen wurde ${ }^{54}$. Mit Nachdruck wurde darin die Meinung vertreten, man sollte zumindest einen Versuch unternehmen, das schwere Los der Rußlanddeutschen durch ihre Umsiedlung nach Deutschland zu wandeln. Die auf knapp 1 Million geschätzten Deutschen der UdSSR würden sich aufgrund des ihnen über Jahrzehnte hinweg zugefügten Leids im nationalsozialistischen Deutschland „als die besten Vorkämpfer gegen den Bolschewismus erweisen "55. Darüber hinaus verspreche die Lösung dieser Frage gerade in der Periode der freundschaftlichen Umgestaltung der deutsch-sowjetischen Beziehungen die Ausschaltung eines „Störmoment[s] ..., das diese Beziehungen immer wieder überschatten müßte" - ein Argument, das der alldeutsch beeinflußte Ausschuß für

\footnotetext{
52 Vgl. die Arbeiten, die in der "Sammlung Georg Leibbrandt“ 1939-41 in Leipzig erschienen; vgl. auch die Bibliographie: Woltner, M., Die rußlanddeutsche Forschung. 1938-1941, in: Deutsches Archiv für Landes- und Volkskunde 6 (1942), S. 376-427.

53 Vgl. Außenpolitisches Amt der NSDAP, Reichsleitung, Amt Osten, gez. Leibbrandt, Reichsamtsleiter, Inf. 1/40, Berlin, 28. Juni 1940, Herrn Geheimrat Lorenz, Auswärtiges Amt; in der Anlage des Schreibens sandte Leibbrandt Lorenz die auf Zeugenaussagen beruhenden Berichte „Die soziale Lage in der Sowjetunion" und „Die Lage des Deutschtums in der Sowjetunion“. AA Inl. II C, Akten betreffend: Förderung des Deutschtums in Rußland, Bd. 4 (1937-44), Nr. 1; sowie: Lage des Deutschtums in der Sowjetunion, zusammengestellt aus Angaben von Rußlandrückkehrern (1938?), BA R 6/104, Ordner 22-28.

54 Aufzeichnung, Pol. V, 12095, Berlin, 14. Dezember 1939, AA Inl. II C, Akten betreffend: Förderung des Deutschtums in Rußland, Bd.4 (1937-1944), Nr.1, D 626 183-85.

5s Aufzeichnung, Pol. V, 12095, ebenda, S. 2.
} 
deutsche Ostpolitik gegen Ende des Ersten Weltkriegs den deutschen Unterhändlern von Brest-Litowsk zu bedenken gegeben hatte.

Ein Erlaß vom 15.12. 1939 ordnete die Prüfung dieser Fragen durch die zuständigen Instanzen an. Auch der deutsche Botschafter in Moskau wurde um seine Stellungnahme gebeten. Graf von der Schulenburg verneinte die Frage, ob von deutscher Seite ein Vorstoß in Richtung auf Umsiedlung der Deutschen aus der UdSSR unternommen werden sollte ${ }^{56}$. Er führte die folgenden Argumente an: Einerseits verhalte sich die Sowjetregierung nach wie vor ablehnend gegenüber jeder Art von Intervention zugunsten einer Gruppe ihrer Bürger. Auch das Aufrollen dieser Frage werde sie folglich als unerwünschte Einmischung in ihre inneren Angelegenheiten betrachten. Ferner könne die Sowjetregierung schon aus Gründen ihres politischen Prestiges in einer solchen Frage nicht nachgiebig sein. Und dies um so mehr, als es sich nicht um eine Frage der Gegenseitigkeit handele. Andererseits bestünden auch in Hinblick auf den Aussiedlungswillen der in Frage kommenden Personen starke Bedenken: „Ein erheblicher Teil der Volksdeutschen in der Sowjetunion ist im Laufe der letzten zwei Jahrzehnte dem Hunger, der Internierung, der Verschickung und dem Terror zum Opfer gefallen. Ein anderer Teil, namentlich die ältere Generation, ist von dem ihm zugefügten Leid derart zermürbt, daß ihm die seelische Kraft zu einem Umsiedlungsentschluß unter den hiesigen Verhältnissen fehlen dürfte. Die jüngere und mittlere Generation ist unter dem Sowjetregime und dem Einfluß der kommunistischen Ideologie aufgewachsen; ihre Verwurzelung im bolschewistischen Staat, die Folge von Russifizierungsbestrebungen und Ehen mit Angehörigen des Russentums mindern ganz erheblich ihre Neigung zur Umsiedlung nach Deutschland. Dies gilt besonders für die Wolgadeutschen; im Kaukasus und in Südrußland hingegen mag es noch wertvollere deutsche Volkssplitter geben. Die in Südrußland zahlreichen Mennoniten werden wenn sie überhaupt auswandern könnten - vorziehen, nach einem Lande zu gehen, in dem keine allgemeine Wehrpflicht besteht. “" ${ }^{57}$

Diese Einschätzung der Lage traf nicht in jeder Hinsicht zu. So hatten die genannten Vernehmungsprotokolle der Rückwanderer aus der UdSSR ergeben, daß unter den Deutschen im Wolgagebiet die Erwartung wach sei, deutsche Schiffe würden bald die Wolga hinaufgefahren kommen, um sie in die Freiheit zu führen. Und die ersten Befragungen von Deutschen in den neu besetzten Gebieten der UdSSR im Sommer 1941 zeigten, daß in den Jahren des deutsch-sowjetischen Nichtangriffspaktes in den deutschen Wohngebieten vielerorts die Hoffnung bestanden hatte, daß nun auch die Umsiedlung dieser Kolonien in Vorbereitung sei. Geschlossene Dörfer hatten sich schon durch Packen und Verladen ihrer Habe auf den Exodus aus Rußland vorbereitet $^{58}$.

${ }^{56}$ Deutsche Botschaft Moskau, Tgb.Nr. E/1/40, Moskau, 2.Januar 1940. Auf den Erlaß vom 15.12. 1939, Pol. V, 12095, Inhalt: Umsiedlung der Volksdeutschen, die innerhalb der früheren Grenzen der Sowjetunion leben. AA Inl. II C, Akten betreffend: Förderung des Deutschtums in Rußland, Bd. 4 (1937-44), Nr. 1, D 626 186-89.

57 Ebenda, S. 2.

58 Vgl. u.a. Panzergruppe 1, Abt. Qu., Gr.H.Qu., den 24.9. 41, „Das Deutschtum im Dnjepr-Gebiet“, GR T 454, R 20, (RMO), F 153-157, hier 156. 
Freilich kann kein Zweifel darüber bestehen, daß der Ansicht des deutschen Botschafters in Moskau schon in dieser Zeit von seiten der eigentlich entscheidenden Ämter des NS-Staates kein Gewicht beigemessen wurde. Denn hatte sich in der Frage der Zuständigkeit für das deutsche Volkstum in der UdSSR schon in der Periode des Aufbaus der neuen NS-Institutionen die Entscheidungsgewalt zunehmend auf die Organe der SS, und hier vor allem auf Lorenz' Vomi verlagert, so wurde dieser Prozeß der Machtkonzentration in den zwei Jahren des Hitler-Stalin-Bündnisses und der Vorbereitungen auf den Krieg mit der UdSSR trotz gegenteiligen äußeren Anscheins nur umso zielstrebiger weiterverfolgt. Die Vorstellungen der SS aber liefen auf einen Einsatz dieser Volksgruppe im Rahmen der nationalsozialistischen Ostsiedlung hinaus. Die „Heimholung ins Reich“, die nur einem neuerlichen Osteinsatz vorgeschaltet sein sollte, hatte sich im Falle der Deutschen aus den baltischen, wolhynischen und bessarabisch-rumänischen Siedlungsgebieten zwar als ein Weg von größerer Sicherheit, zugleich aber als eine Strecke außerordentlicher Strapazen für die Betroffenen und finanzieller Lasten für die Umsiedlungsstäbe der SS erwiesen. Hunderttausende von Umsiedlern befanden sich noch in den von der Vomi geleiteten Lagern und warteten auf „Ansetzung“ und Kompensation für ihre in der Heimat zurückgelassenen Besitztümer. Im Falle der Rußlanddeutschen schienen sich einfachere Wege anzubieten.

\section{Die Pläne Himmlers, Rosenbergs und Hitlers}

Am 7. Oktober 1939, einen Tag nach der Reichstagsrede Hitlers mit der Ankündigung einer Neuordnung der völkisch-geographischen Räume Osteuropas, wurde der Reichsführer SS Heinrich Himmler mit Führererlaß zum Reichskommissar für die Festigung deutschen Volkstums (RKF) ernannt ${ }^{59}$. Die Kompetenz Himmlers als RKF erstreckte sich auf drei Aufgabenbereiche:

Die erste Aufgabe betraf die Rückführung („Heimholung ins Reich“) der in der nunmehr sowjetischen Interessensphäre Ostmitteleuropas lebenden Deutschen (Volksund Reichsdeutschen). Diese Aktion, die sog. Vertragsumsiedlung ${ }^{60}$, führte 751460 Deutsche aus den Gebieten der „völkischen Feldbereinigung “ zwischen der stalinistischen UdSSR und dem Deutschland Hitlers nach Deutschland ${ }^{61}$. Unter ih-

59 RKFdV oder kurz: RKF genannt; vgl.: Erlaß des Führers und Reichskanzlers zur Festigung deutschen Volkstums vom 7. Oktober 1939, GR T 81, R 266, F 2384344-7. Die Zusammenstellung der Anordnungen des RKF befindet sich in GR T 81, R 266, F 2384180-6. Siehe auch: Koehl, R.L., RKFDV; German Settlement and Population Policy, 1939-1945. A History of the Reich Commission for the Strengthening of Germandom, Cambridge/Mass. 1957.

60 Bohmann, S., Menschen und Grenzen. Strukturwandel der deutschen Bevölkerung im sowjetischen Staats- und Verwaltungsbereich, Köln 1970, S.74ff.

61 Eine zusammenfassende Darstellung steht noch aus; zum Stand der Literatur für einzelne Gruppen: Aus nationalsozialistischer Sicht: Der Treck der Deutschen aus Wolhynien, Galizien und dem Narew-Gebiet, Berlin 1943; Der Zug der Volksdeutschen aus Bessarabien und Nordbuchenland, Prag 1942; Albrecht, I., Zur Bibliographie der Umsiedlung, in: Deutschtum im Ausland. 
nen befanden sich Zehntausende von Deutschen aus den baltischen Ländern ${ }^{62}$, Wolhynien und Bessarabien, die bzw. deren Vorfahren bis 1918 Teil der deutschbaltischen oder deutschrussischen Bevölkerung und russische Untertanen gewesen wa-

Zeitschrift des Deutschen Auslandsinstituts Stuttgart, 27.Jg., Mai-Juni 1944, Heft 5/6, S. 82 ff. Neuere Literatur: Rimscha, H.v., Die Umsiedlung der Baltendeutschen aus Lettland im Jahre 1939. Eine Betrachtung, Hannover-Döhren 1959; Kroeger, E., Der Auszug aus der alten Heimat. Die Umsiedlung der Baltendeutschen, Tübingen 1967; Loeber, D. (Hrsg.), Die diktierte Option. Die Umsiedlung der Deutschbalten aus Estland und Lettland 1939-1941, Neumünster 1974.

62 Es ist bekannt, daß die Ansichten der Deutschbalten über diese „Heimholung ins Reich“ durchaus geteilt waren. Zwar hatte die Mehrheit der deutschbaltischen Zeitungen, die in den Jahren seit der Machtergreifung des Nationalsozialismus auf einen „völkischen" Kurs gebracht worden waren, die Bekanntgabe der Umsiedlungsverträge mit Enthusiasmus gefeiert. Die liberalere und zögernde Stimme von H.v. Rimscha aber fand ebenfalls weites Gehör. Interessanterweise hat der 77jährige Ernst Seraphim in Hitlers Umsiedlungsverträgen einen Bruch mit der bisherigen Reichspolitik gesehen, über den er nicht schweigen konnte. Er verfaßte am 3.11. 1939 ein Schreiben, das uns nur ausschnittweise zur Verfügung steht; darin hieß es u. a.: „Sie werden mit uns Balten mitempfinden, wie tief und schmerzlich wir alle die Tragödie der Aussiedlung aus unserer alten geliebten Heimat empfinden, und wie wenig wir - einige junge Elemente abgerechnet - uns mit dem Bruch der bisherigen Reichspolitik und der Liquidierung einer Jahrhunderte alten Tradition innerlich befreunden können, brauche ich Ihnen nicht zu sagen. Wir haben doch wohl alle in der älteren Generation das Gefühl, daß der Preis, den wir Moskau gezahlt haben, ein zu hoher gewesen ist. Sind wir recht unterrichtet, so lag es in der Absicht der Regierung, dieDüna zur Grenze der beiden Interessengebiete zu machen und das baltische Element in Kurland gemeinsam konzentrieren zu wollen. Aber Moskau beharrte auf Kurland als Aequivalent für unsere Demarkationslinie am Bug statt an der Weichsel. Heute ist nun auch nichts mehr zu ändern, aber das Herz ist wund und die Ratio fragt: wozu? Doch das ist, um mit Fontane zu reden, ,ein viel zu weites Feld! " (An L. [eibbrandt? I. F.] Auszug aus Schreiben von Dr. E. Seraphim, Königsberg i. Pr., vom 3.11. 1939, Gri/Re. 11.11. 39, GR T 81, R 274, F 2393796) Der Auszug wurde vermutlich vom Deutschen Auslandsinstitut Stuttgart, an das der Brief wohl gerichtet war, an das Amt Osten des APA der NSDAP geschickt.). Am 17. 10. 1939 hatte ein Schreiben aus Berlin, gerichtet an Prof. Csaki, den Direktor des DAI, vermerkt: „Unter Geheim noch Folgendes: Die Balten haben wohl nach der ersten begreiflichen Panik ihre Haltung wiedergefunden und scheinen sich mit der Ansiedlung in Westpreußen zu befreunden.“ (GR T 81, R 274, F 2393798). Um „die Verpflanzung der Balten ins Reich" erleichtern zu helfen, verfaßte Max Hildebert Boehm, jetzt Professor in Jena, einen Artikel unter dem Titel „Seelische Umsiedlung“; darin wies er die Umsiedlungsstäbe darauf hin, daß neben den praktischen und wirtschaftlichen Fragen der Umsiedlung der Deutschbalten die psychische Seite nicht vernachlässigt werden dürfe (veröffentlicht in: Münchner Neueste Nachrichten vom 11.2. 1940; Baltischer Beobachter 11 (1940), S. 55 f.; Volksforschung, 30.3. 1943, Heft 1/2, S. 133-37). Nicht alle Deutschbalten folgten dem Ruf „Heim ins Reich“ einhellig. Während sich unter den Umsiedlern der Litauen-Aktion ein Nachkomme des Generals Graf Totleben, des Verteidigers von Sewastopol, und Nadine Solov'ev, geb. von Wieland, eine Urgroßnichte des deutschen Dichters Wieland, befand, erklärte Kasimira von Hindenburg, Erbadlige des Gouvernements Kiew, am 5. Februar 1941 bei der Registrierung durch den Deutschen Ortsbevollmächtigten und den sowjetischen Vertreter der Umsiedlungskommission in Wilna, sie komme für die Umsiedlung nicht in Frage, denn sie sei Polin. Als die beiden Kommissionsmitglieder erklärten, sie seien bereit, im Falle der alten Dame eine Ausnahme zu machen, teilte sie ihnen mit, sie werde nur ausreisen, wenn eine polnische Freundin, die sie bei sich aufgenommen habe, mitreisen dürfe. Als dies verneint wurde, verzichtete sie auf die Ausreise. „Und, als wenn sie der Schritt, den sie unternommen hatte, gereute, griff sie schnell nach ihren Papieren, packte sie in ein schmutziges Stück Zeitungspapier ein, nickte freundlich und verließ mit eiligen Schritten das Registrierlokal." (GR T 

Lorenz.

Die zweite Aufgabe Himmlers in seiner Eigenschaft als RKF war definiert als „Ausschaltung des schädigenden Einflusses von solchen volksfremden Bevölkerungsteilen, die eine Gefahr für das Reich und die deutsche Volksgemeinschaft bedeuten". Sie bezog sich sowohl auf die Gebiete des Großdeutschen Reiches als auch auf die eingegliederten und künftigen besetzten Gebiete des europäischen Ostens und bestand unter anderem in einer verschärften Anwendung der Nürnberger Gesetze auf den osteuropäischen Raum. Himmler hat diese Aufgabe zu einem Teil an Heydrich als dem Chef der Sicherheitspolizei und des SD weiterübertragen, versäumte es aber nicht, sich durch Absprachen mit Heydrich intensivste Zusammenarbeit zu sichern. Diese Absprachen sollten in der Praxis zu enger Koordination der Dienststellen und Organe Heydrichs, vor allem der Einsatzgruppen, mit den Dienststellen und Ämtern Himmlers, unter anderen der Vomi von Lorenz und der Dienststelle Ulrich Greifelts (s.u.), führen. Die Praxis der „Abschiebung“ und Vernichtung unerwünschter „Fremdvölkischer" war so von Anfang an mit der Tätigkeit der „Erfassung“ und des „Einsatzes“ der Volksdeutschen im osteuropäischen Raum aufs engste verbunden.

Die dritte Aufgabe des RKF, die "Gestaltung neuer deutscher Siedlungsräume“, "Seßhaftmachung"von Siedlern und Schaffung eines neuen deutschen Bauerntums in Osteuropa aus Volks- und Reichsdeutschen, schloß auch eine Neuverteilung des deutschen Bauerntums in den später zu besetzenden Teilen Osteuropas ein.

Himmler verstand die mit seiner Ernennung zum RKF verbundenen Aufgaben als einen Führerauftrag ,übergeordneter Natur"64. Dies bedeutete in der Praxis, daß die meisten der obersten Reichsbehörden und zentralen Dienststellen Verbindungsreferenten zum Reichskommissar berufen mußten, der Reichskommissar sich aber auf-

81, R 293, F 2418542 f., sowie ebenda, F 2418535 ff., die Fälle Totleben und Wieland) Mit der sowjetischen Übernahme Litauens verwischten sich die Spuren der mutigen Frau. - Nach der Rückeroberung ihrer Heimatgebiete durch die deutsche Wehrmacht war es den in Deutschland angesiedelten oder noch in Lagern befindlichen Deutschbalten (A-Fällen) unter Strafe verboten, in ihre Heimat zurückzukehren. Der Erlaß des RKF vom 19.8. 1941 sagte ausdrücklich, daß die Wiederbesiedlung der baltischen Provinzen mit früheren deutschbaltischen Umsiedlern „grundsätzlich nicht in Frage" komme. Diese Regelung galt für die gesamte Besatzungszeit ohne Unterbrechung und wurde mit der zunehmenden Zahl "unerlaubt eingereister A-Fälle“ in die baltischen Provinzen noch verschärft. Im Oktober 1943 wurde für die unerlaubt eingereisten Deutschbalten die Abschiebung in Straf- und Konzentrationslager angeordnet. (GR T 580, R 747, Reichskommissar für die Festigung deutschen Volkstums, Stabshauptamt, I-1, 1-7-5, Dr. M./B., Berlin, den 19. 10. 1943; diesem Dokument zufolge war bekanntgeworden, daß sich allein in Litauen etwa 800 bis 1000 unerlaubt eingereister A-Fälle unkontrolliert „herumtrieben“. Zwecks Abschreckung seien die hiervon Aufgegriffenen „am zweckmäßigsten ... in das Straflager Pravenischken abzuschieben". Ferner sollten die Sicherheitspolizei und der SD des Kommandos Kauen sowie die SS Fahndungen anstellen. Außerdem sollten alle O-Fälle, die im Reich lebten, einen sofortigen Stop für Besuche bei O-Fällen in Litauen erhalten.)

63 Vgl. „Übersicht über die Umsiedlung der Umsiedlungs-Treuhand G.m.b.H. nach Jahresbericht vom Jahre 1941“, DAI-LC, F-144, 8393.

${ }^{64} \mathrm{Vgl}$. Reichsverwaltungsbl. Bd.61, Heft 23, Berlin, 8.6. 1940. 
grund dieses seines unmittelbaren Führerauftrags jederzeit über andere Behörden hinwegsetzen und ungeachtet derer Befugnisse eigene Anweisungen erteilen konnte. Die Dienststelle des Reichsführers SS Reichskommissar für die Festigung deutschen Volkstums in Berlin bestand aus mehreren Hauptabteilungen. Hauptabteilung I war als Planungsabteilung unter anderem für die Ostraumplanung, d.h. die Germanisierung des Bodens in Osteuropa, zuständig. Hauptabteilung II, die Hauptabteilung für Volkstumsarbeit und „Lenkung des Menscheneinsatzes“ der Volksdeutschen, Mitte 1941 auf die Ebene eines „Stabshauptamtes des Reichskommissars für die Festigung deutschen Volkstums" erhoben, unterstand SS-Obergruppenführer Ulrich Greifelt ${ }^{65}$; unter den acht Ämtern dieses Stabshauptamtes befand sich auch das Siedlungsamt. Greifelts Stabshauptamt war im wesentlichen für die Erfüllung der dritten Aufgabe des RKF zuständig.

Mit der Neuordnung der Siedlungsräume im Osten und der Germanisierung des Bodens war auch die Frage der „rassischen Siebung “ verbunden ${ }^{66}$. Als Instrument dafür wurde die Deutsche Volksliste (DVL) entwickelt. Ihre Anwendung ordnete der Führererlaß vom 8. Oktober 1939 an. Die Durchführung lag offiziell beim Reichsminister des Innern „im Einvernehmen mit dem Reichsführer SS Reichskommissar für die Festigung deutschen Volkstums ${ }^{\text {(667) }}$, d.h. in der Praxis bei Himmler und seinen Dienststellen. Zunächst galt sie nur für die ehemaligen polnischen und Danziger Staatsangehörigen deutscher Herkunft ${ }^{68}$; durch Verordnung vom 4. März 1941 wurde sie zu einer allgemeinen Regelung erhoben ${ }^{69}$. Die DVL bestand aus vier Abteilungen ${ }^{70}$ :

Abteilung 1 umfaßte Volksdeutsche, die in ihrem Herkunftsland als Nationalisten bzw. Nationalsozialisten aktiv gewesen waren, nach Greifelts Aussage „die wirklich aktiven Deutschen"71.

Abteilung 2 schloß sog. reine Deutsche ein, die - nach Greifelt - „ihr Deutschtum bewahrt hatten", aber keine aktiven Deutschtumskämpfer waren.

Personen, welche die Aufnahmebedingungen der Abteilungen 1 und 2 erfüllten, hatten das Recht auf sofortigen Erwerb der deutschen Staatsbürgerschaft, d. h. sie konnten Reichsdeutsche werden.

In Abteilung 3 der DVL konnten Personen aufgenommen werden, die „deutsches

${ }^{65} \mathrm{Vgl}$. Greifelt, U., Interrogation Summary Nr.1514, Interrogation Nr.872, 14. März 1947, NA, Record Group 238, S. $3 \mathrm{ff}$.

$66 \mathrm{Vgl}$. Ackermann, Himmler, S. $207 \mathrm{ff}$.

67 Verordnung über die Deutsche Volksliste und die deutsche Staatsangehörigkeit in den Eingegliederten Ostgebieten, in: Außendeutscher Wochenspiegel (AdW), Folge 10, 14.3. 1941.

68 Vgl. Broszat, M., „Erfassung“ und Rechtsstellung von Volksdeutschen und Deutschstämmigen im Generalgouvernement, in: Gutachten des Instituts für Zeitgeschichte, Band II, Stuttgart 1966, S. 243-60.

69 Vgl. Reichsgesetzbl.I, 1941, S. 118 ff., in Verbindung mit dem Runderlaß vom 13.3. 1941 - Ic 5125/41-5000 Ost.

70 Vgl. dazu: Trials of the War Criminals before the Nuremberg Military Tribunal under Control Counsel Law Nr.10, Oct. 1946-April 1949, Band V, Washington D.C. 1950, S. $120 \mathrm{ff}$.

71 Greifelt, U., Interrogation Summary Nr.1633, 21. März 1947; Interrogation Nr.872 C, NA, Record Group 238, S.6. 
Blut" besaßen und deutsche Herkunft nachweisen konnten, sich aber an die andersethnische Umwelt assimiliert hatten (Greifelt: „nachlässige Deutsche“). Der Grad ihrer Assimilation mußte allerdings für so gering befunden werden, daß sie für fähig galten, für das „Deutschtum zurückgewonnen“ zu werden. Abteilung 3 schloß auch „rassisch hochwertige“, „eindeutschungsfähige“ „fremdvölkische“ Ehepartner von Volksdeutschen der Abteilungen 1 und 2 ein. Personen der Abteilung 3 der DVL hatten ein Recht auf die deutsche Staatsbürgerschaft auf Widerruf, wobei für den Einbürgerungsprozeß zehn Jahre angesetzt waren. In dieser Zeit unterlagen sie bereits dem deutschen Recht und mußten alle Pflichten, einschließlich der Wehrpflicht, erfüllen ${ }^{22}$. Personen der Abteilungen 1 und 2, die keine Einbürgerung anstrebten, sowie diejenigen Personen der Abteilung 3, die feindseliges Verhalten gegenüber der deutschen Besatzungsmacht zeigten, mußten mit ihrer „Abschiebung“ rechnen. Personen, die trotz Aufforderung oder Belehrung keinen Antrag auf Aufnahme in die DVL stellten, konnten zur Aufnahme dieses Verfahrens gezwungen oder aber dem SD überstellt und in ein Konzentrationslager „abgeschoben“ werden" .

Abteilung 4 der DVL umfaßte Personen, die mindestens 50\% „deutsches Blut" aufwiesen, sich aber vom Deutschtum abgewandt hatten (nach Greifelt: „Renegaten“

72 GR T 81, R 265, F 2384043, RKF Anordnung 50/1, Berlin, 30.9. 1941, „Rassische Musterung der Angehörigen der Abt. 3 der Deutschen Volksliste"; eine besondere rassische Musterung wurde bei zweifelhaften Fällen angeordnet. Bei negativem Ergebnis dieser Musterung konnte die Streichung aus der DVL vorgenommen werden.

${ }^{73}$ Vgl. Trials, Band V, S. 129 ff.; Greifelt, U., Interrogation Summary Nr.1589, Interrogation Nr. 872 a (14. März 1947), NA, Record Group Nr.238, S. 18; ferner die Beispiele in Broszat, „Erfassung".

Siehe: Anweisung des Reichsministers des Innern, I Sta R 5264/44/4160, GR T 81, R 265, F 2384029 f.: „Falls sich einwandfrei deutschstämmige Personen und Fremdstämmige, die als völlig eingedeutscht anzusehen sind, trotz Belehrung weigern sollten, Anträge auf Anerkennung als deutsche Staatsangehörige zu stellen, so ist in Form einer Niederschrift ausdrücklich festzuhalten: daß sie trotz Belehrung auf den Erwerb der deutschen Staatsangehörigkeit keinen Wert legen; weiter ist hiervon der zuständige SD-Leitabschnitt zu verständigen, der gegenüber Deutschstämmigen nach den Grundsätzen des abschriftlich anliegenden RdErl. des Reichsführers SS und Chefs der Deutschen Polizei vom 16.2.1942 - S I A 2, Nr.420 VII/41-176 verfahren wird. Dieser RdErl. wird demnächst vom Reichssicherheitshauptamt auch auf die außerhalb der eingegliederten Ostgebiete befindlichen deutschstämmigen Antragverweigerer ausgedehnt werden. " Dazu anliegend (GR T 81, R 265, F 2384031) Abschrift. Der Reichsführer SS und Chef der Deutschen Polizei Reichskommissar für die Festigung deutschen Volkstums, S I A 2, Nr.420 VII/41-176, Berlin, 16. Febr. 1942, „Betr.: Deutschstämmige, die ihre Eintragung in die Deutsche Volksliste nicht beantragen.

1.Ich ersuche, die nachgeordneten Dienststellen anzuweisen, die Deutschstämmigen, die ihre Eintragung in die Deutsche Volksliste nicht beantragen, der örtlich zuständigen Staatspolizei(leit)stelle namhaft zu machen. Uber das Veranlaßte ist zu berichten.

2. Die örtlich zuständigen Staatspolizei(leit)stellen haben den ihnen namhaft gemachten Personen zur Auflage zu machen, innerhalb einer Frist von 8 Tagen nachzuweisen, daß der Antrag auf Eintragung in die Deutsche Volksliste gestellt ist. Wird der Nachweis nicht erbracht, so ist der Betreffende in Schutzhaft zu nehmen und seine Überführung in ein Konzentrationslager zu veranlassen. gez. Himmler." 
oder Deutsche, die sich „mit dem fremden Volkstum stark eingelassen hatten“). Zu ihnen gehörten in Polen auch Deutsche, die angeblich antideutschen, polnischen Organisationen angehört hatten ${ }^{74}$. Personen, die der Abteilung 4 zugerechnet wurden, galten allgemein als „menschlicher Abfall“, der aus den Reihen des deutschen Volkes "auszusondern" sei. Er wurde in Vorberechnungen von Rosenberg und Frauenfeld in Hinblick auf die Deutschen der Sowjetunion auf $10-15 \%$ veranschlagt ${ }^{74 a}$. Es läßt sich schwer nachprüfen, wie viele Deutsche in den besetzten Ostgebieten tatsächlich das Schicksal erlitten, das diesen „Abfallprodukten“ des Volksdeutschtums im europäischen Osten zugedacht war. Obwohl einzelne Fälle bekannt sind und namhaft gemacht werden können, wurde die Abteilung 4 bei Zahlenangaben über das Volkslistenverfahren in den besetzten sowjetischen Gebieten niemals aufgeführt. Die Geheimhaltung in Fragen der Abteilung 4 der DVL reichte so weit, daß in den entsprechenden Anweisungen zur Behandlung der Angehörigen der einzelnen Abteilungen der DVL die der Angehörigen der Abteilung 4 in der Regel ausgespart blieb. Dies soll durch zwei Fälle verdeutlicht werden.

So wurden in den „streng vertraulichen“ Anordnungen, die Lorenz als Leiter des Hauptamtes Volksdeutsche Mittelstelle zur Behandlung der „Baltennachumsiedler und Baltenflüchtlinge "74b , erließ, folgende Grundsätze zur Einstufung angegeben:

„Gruppe I: Volksdeutsche, die sich aktiv am Volkstumskampf im Herkunftsgebiet beteiligt haben.

Gruppe II: Volksdeutsche und Mischehen. Letztere müssen im Herkunftsgebiet im deutschen Volkstum aufgegangen sein. Beide Personengruppen sind politisch indifferent.

Gruppe III: Fremdstämmige und Mischehen, die sich im Herkunftslande nicht zum Deutschtum bekannt haben.

Gruppe IV: Volksdeutsche und Fremdstämmige, die politisch verdächtig und belastet sind."

Angehörige der Gruppen I und II sollten als Umsiedler anerkannt und im Schnellverfahren eingebürgert werden. Die Angehörigen der Gruppe III waren für die Dauer des Krieges für einen Arbeitseinsatz im Reich vorgesehen. Sie konnten eine Erklärung abgeben, in der sie ihren Willen bekundeten, die deutsche Staatsangehörigkeit zu erwerben und ständigen Wohnsitz auf deutschem Reichsgebiet zu nehmen. „Daraufhin werden Untersuchungen in gesundheitlicher und rassischer Hinsicht veranlaßt. So-

74 Vgl. GR T 81, R 268, F 2409584 f., „Zusammenstellung der deutschfeindlichen polnischen Organisationen “ und Zusammenstellung von 233 in der „volksdeutschen Kartei“ enthaltenen Karten von Personen, die selbst oder deren Angehörige diesen Organisationen angehörten.

74 a A. Rosenberg in seinen Umsiedlungsplänen der Deutschen des Wolgagebietes und Gauleiter A. E. Frauenfeld über die Umsiedlung der Deutschen aus Südtirol auf die Krim in der Denkschrift über die Möglichkeit der geschlossenen Umsiedlung der Südtiroler nach der Krim, 1941-42; GR T 175, R 53, F $2567508 \mathrm{ff}$.

$74 \mathrm{~b}$ Reichskommissar für die Festigung deutschen Volkstums. Hauptamt Volksdeutsche Mittelstelle (sic) - Völkische Schutzarbeit -, Berlin, den 15. Febr. 1943, An den Gaubeauftragten der Volksdeutschen Mittelstelle - Völkische Schutzarbeit, GR T 81, R 266, F 2384114 f. 
bald diese ein positives Ergebnis zeitigen, werden die betreffenden Herdstellen in ein sogenanntes Eindeutschungsverfahren eingeschaltet, mit dessen Durchführung der für den Wohnort zuständige Höhere SS- und Polizeiführer beauftragt wird." Sog. Mischfälle, „bei denen der deutsche Blutsanteil überwiegt", sollten ohne Befragen nach dem Grundsatz „zur Erhaltung deutschen Blutes“ automatisch in ein Eindeutschungsverfahren einbezogen werden. Die Behandlung der Angehörigen der Gruppe IV ist nicht explizit genannt.

Am 9.2. 1942 gab Himmler die „Allgemeine Anordnung Nr.12/C über die Behandlung der in die Deutsche Volksliste eingetragenen Personen " ${ }^{\text {"7c }}$ heraus. Sie nahm bezug auf seinen Erlaß über die Überprüfung und Aussonderung der Bevölkerung in den eingegliederten Ostgebieten vom 12. September 1940 (I/KO 3b/23.3. 40), welcher die Grundsätze zur Aussonderung der Bevölkerung in den neuen Ostgebieten und zur Aufnahme in die Deutsche Volksliste festgelegt hatte; außerdem bezog sie sich auf die Verordnung über die einheitliche Anwendung der DVL in den eingegliederten Ostgebieten vom 4.März 1941 (RGBl. I, S.118) und die näheren Bestimmungen zur Aufnahme in die einzelnen Abteilungen der DVL, die der Reichsminister des Innern im Einvernehmen mit der Parteikanzlei und dem Reichsführer SS RKF durch Erlaß vom 13. März 1941 (Ic 5125/41-5000 Ost) getroffen hatte. Auf der Grundlage dieser Bestimmungen ordnete Himmler die folgende Behandlung der Angehörigen der einzelnen Abteilungen an:

„A. Behandlung der Angehörigen der Abt. 1 und 2 der Deutschen Volksliste.

In den Abt. 1 und 2 der Deutschen Volksliste sind diejenigen Volksdeutschen erfaßt, die sich vor dem 1. September 1939 im Volkstumskampf aktiv für das Deutschtum eingesetzt oder sich ihr Deutschtum nachweislich bewahrt haben.

Die Angehörigen der Abt. 1 und 2 der Deutschen Volksliste erwerben ohne Rücksicht auf den Tag ihrer Aufnahme mit Wirkung vom 1.9.39 bzw. 26.10. 39 die deutsche Staatsangehörigkeit mit den damit verbundenen Rechten und Pflichten."

Die Anordnung vermerkte, daß die Unterscheidung dieser beiden Kategorien von Volksdeutschen „nur für den inneren Dienstgebrauch der Deutschen Volksliste und für partei-interne Zwecke vorgesehen" sei. In die Partei konnten gemäß der Anordnung der Parteikanzlei vorerst nur die Angehörigen der Abt. 1 der DVL aufgenommen werden.

„B. Behandlung der Angehörigen der Abt. 3 der Deutschen Volksliste.

In der Abt. 3 der Deutschen Volksliste sind folgende Personen erfaßt:

a) Deutschstämmige, die im Laufe der Jahre Bindungen zum Polentum eingegangen sind, die aber aufgrund ihres Verhaltens die Voraussetzungen dafür in sich tragen, wieder vollwertige Mitglieder der deutschen Volksgemeinschaft zu werden.

b) Personen nichtdeutscher Abstammung, die in völkischer Mischehe mit einem

${ }^{74 c}$ Der Reichsführer-SS Reichskommissar für die Festigung deutschen Volkstums, Führerhauptquartier, den 9.2. 1942, GR T 81, R 266, F 2384292-9. 
deutschen Volkszugehörigen leben, in der sich der deutsche Teil durchgesetzt hat.

c) Die Angehörigen der völkisch nicht klar einzuordnenden, blutsmäßig und kulturell jedoch zum Deutschtum hinneigenden Bevölkerungsgruppen mit slawischer Haussprache, soweit sie sich nicht schon vor dem 1.September 1939 zum deutschen Volkstum bekannt haben oder soweit sie für eine Aufnahme in die Deutsche Volksliste deshalb nicht in Frage kommen, weil sie rassisch ungeeignet sind, oder sich aktiv gegen das Deutschtum betätigt haben oder aus sonstigen Gründen im Einzelfall als unerwünschter Bevölkerungszuwachs anzusehen sind."

In ihrer neuen rechtlichen Stellung sollten Angehörige der Abteilung 3 der DVL "durch unverzügliche Einbürgerung die deutsche Staatsangehörigkeit auf Widerruf" erwerben. „Binnen $10 \mathrm{Jahren}$ können der Reichsminister des Innern im Einvernehmen mit meinem Stabshauptamt oder die von ihnen bestimmten Stellen den Erwerb der deutschen Staatsangehörigkeit widerrufen. Ein solcher Widerruf wird insbesondere in Frage kommen, wenn der Versuch einer Wiedereindeutschung oder Eindeutschung als mißlungen anzusehen ist."

Im Laufe dieser 10-Jahresfrist unterlagen die Angehörigen der Abteilung 3 einer Reihe von besonderen Maßnahmen.

Im Rahmen ihrer sicherheitspolizeilichen Behandlung wurde die Einschränkung ihrer Freizügigkeit angeordnet. „Die Angehörigen der Abt. 3 der Deutschen Volksliste sind den Aufenthaltsbeschränkungen zu unterwerfen, die sich zwangsläufig aus dem Eindeutschungszweck ergeben. Ihr Einsatz soll grundsätzlich nur im Altreich erfolgen. Insbesondere kann ihnen, soweit es die Lage des Arbeitseinsatzes oder ein Bedürfnis zur Bereitstellung ihres bisherigen Grundbesitzes für andere Zwecke ... erfordert, über die zuständige Staatspolizei(leit)stelle aufgegeben werden, die Ostgebiete zu verlassen. Eine Rückkehr bereits ausgesiedelter Personen in die Ostgebiete ist ebenso wie eine Übersiedlung in das Ausland oder in die Kolonien nicht statthaft ... Auch im Gebiet des Altreiches können bestimmte Wohngebiete gesperrt werden."

Bezüglich der Wiedereindeutschung war eine spezielle Überwachung angesetzt. „Die Angehörigen der Abt. 3 der Deutschen Volksliste bedürfen in ihrer Gesamthaltung zum Deutschtum einer systematischen Ausrichtung und Festigung. Die Erziehung zum Deutschtum ist Aufgabe der Partei. Sie hält hierbei Verbindung zu meinem Stabshauptamt und dem Reichsminister des Innern. Die Betreuungs- und Überprüfungsergebnisse sind dem Stabshauptamt oder meinen Beauftragten nach Aufforderung jederzeit bekanntzugeben. Die Partei entscheidet im Einvernehmen mit dem Stabshauptamt nach Anhören der Kreispolizeibehörde im Einzelfall darüber, ob und wann das Eindeutschungsziel erreicht ist."

Die Anordnungen über die rechtliche Stellung der Angehörigen der Abteilung 3 der DVL bzw. über ihre Stellung im öffentlichen Leben legten fest, daß diese Personen nicht in die Partei, wohl aber in die Gliederungen der Partei aufgenommen werden konnten. Sie wurden zur Ableistung eines Pflichtjahres gezwungen und galten mit ihrer Aufnahme in die DVL als reichsarbeits- und wehrdienstpflichtig. Sie durften nicht 
in das Beamtenverhältnis übernommen, konnten im öffentlichen Dienst jedoch in untergeordneten Positionen eingestellt werden. Die Übernahme öffentlicher oder sonstiger Ehrenämter war ihnen verwehrt. Eheschließungen und Adoptionen zwischen Angehörigen der Abteilung 3 der DVL oder mit deutschen Staatsangehörigen waren statthaft. „Sonstige Eheschließungen (z. B. mit Angehörigen der Abt. 4, mit Fremdvölkischen oder mit deutschen Staatsangehörigen auf Widerruf, die nicht der Abt. 3 der Deutschen Volksliste angehören) sind unzulässig." Eheschließungen von Angehörigen der Abteilung 3 der DVL mit politischen Leitern der NSDAP, Führern der Partei-Gliederungen, Offizieren, Angehörigen des Reichsarbeitsdienstes, Beamten und Behördenangestellten bedurften der besonderen Genehmigung des Stabshauptamtes des RFSS RKF. Ausbildung und Zugang zu bestimmten Berufen konnten den Angehörigen der Abteilung 3 auf Antrag genehmigt werden oder auch „versperrt bleiben“. Die vermögensrechtliche Behandlung der Angehörigen der Abteilung 3 der DVL sah unter anderem die Beschlagnahme ihrer Grundstücke oder bestehender Gewerbebetriebe „als Sicherungsmaßregel bis zum Fortfall des Widerrufes" vor. Im Falle landwirtschaftlicher Grundstücke erstreckte sich die Beschlagnahme auch auf das Zubehör, bei Gewerbebetrieben auf das Inventar. Die Beschlagnahme von Immobilien jeder Art hatte zusätzlich den Zweck, „jede Verwurzelung dieser Personen in den Ostgebieten für die Zukunft auszuschließen“.

Die faktische Enteignung, das Bestehen der sicherheitspolizeilichen Überprüfung und besonders die Erfüllung der Pflichten deutscher Staatsbürger, allen voran die Wehrpflicht, genügten aber nicht, um die rassenpolitischen Verdachtsmomente von den Angehörigen der Abteilung $3 \mathrm{zu}$ wenden. So warnte Himmler u. a. davor, den Angehörigen dieser Gruppe, die das Eiserne Kreuz Zweiter Klasse erworben hatten, die deutsche Staatsbürgerschaft zu verleihen ${ }^{74 d}$.

Der Absatz „Behandlung der Angehörigen der Abt. 4 der Deutschen Volksliste“ besagte lediglich: „Über die Behandlung der in Abt. 4 der Deutschen Volksliste eingetragenen Personen ergeht Sonderanordnung."

Zur Prüfung strittiger Fälle bei der Durchführung der Prozedur der DVL war der Oberste Prüfungshof der Deutschen Volksliste geschaffen worden; er war der Dienststelle Greifelts angegliedert ${ }^{75}$.

Während die Aufnahme in die Deutsche Volksliste vor Ort vorgenommen wurde, fand in den Einwandererzentralen (EWZ) ${ }^{76}$ für volksdeutsche Umsiedler eine zweite rassenpolitische Überprüfung und Klassifizierung statt. Sie bezog sich auf die Ein-

${ }^{74 \mathrm{~d}}$ Himmler in seiner ersten Rede in Posen, Nbg. Dok. PS-1919.

75 Greifelt, U., Interrogation Summary Nr. 1589, Interrogation Nr. 872 a, S. 18, 20.

76 Die Einwandererzentralen (EWZ) waren Dienststellen des RFSS RKF, mit deren Aufbau und Organisation Himmler den Chef der Sicherheitspolizei und des SD, SS Gruppenführer Heydrich, sowie nach dessen Ermordung dessen Nachfolger Kaltenbrunner beauftragt hatte; vgl. u. a.: Die Arbeit der Einwandererzentrale Posen, GR T 81, R 266, F 2384208-12, sowie GR T 580 (RMVP), R 700-722 (Akten des Führungsstabs der EWZ, Allgemeine Richtlinien und Verfügungen für die Jahre 1942-1944 sorvie Schleusungsbestimmungen für Rußlanddeutsche aus dem Jahre 1944). 
satzmöglichkeit im Rahmen der Siedlungspolitik und unterschied zwischen A-, Ound S-Fällen. O- oder Ost-Fälle waren Personen, die aufgrund „hoher rassenpolitischer Kennzeichen“ für den Ost-Einsatz („Ansetzung“ auf Ostland) vorgesehen waren; sie sollten in der Lage sein, das „Großdeutsche Reich“ im Osten selbständig zu verteidigen (das galt besonders für den Kampf gegen Partisanen). A- oder AltreichFälle waren Personen, die nicht als zuverlässig und qualifiziert für den Osteinsatz galten; sie sollten daher zunächst im Altreich (auf eigentlich deutschem Boden) in Durchgangslagern durch Schulung und Arbeitseinsatz an das nationalsozialistische Deutschland angepaßt werden, bevor man über ihren weiteren Einsatz entscheiden würde. Die Definition von A- und O-Fällen lautete: „Ein O-Fall ist grundsätzlich jeder Umsiedler, der die Rassewertungsgruppe 1 bis 3 hat, die Einbürgerung erhält und in der politischen Wertung keine 5 (dies bedeutet, daß er politisch nicht belastet ist); weiterhin, wenn ärztlicherseits keine Bedenken bestehen (erbkrank). Ein A-Fall sind alle die Umsiedler, die einen Einweisungsbescheid erhalten, also nicht sofort bei der Durchschleusung eingebürgert werden, Rassewertungsgruppe 4 haben, erbkrank sind und bei denen der Arzt feststellt, daß sie für den Osteinsatz nicht geeignet sind."76a

Als S-(Sammellager-)Fälle wurden Personen eingestuft, die nicht nur als unzuverlässig für den Osteinsatz, sondern im derzeitigen Zustand überhaupt für ungeeignet angesehen wurden, mit dem nationalsozialistischen Deutschland in Berührung zu kommen. Dementsprechend waren sie zunächst einer Aktivpropaganda zu unterziehen und durch Arbeitsprogramme auf „deutsche Arbeitsleistung“ vorzubereiten; dies konnte viele Monate, ja sogar Jahre in Anspruch nehmen.

Die EWZ wiesen die klassifizierten Personen je nach ihrem rassen- und siedlungspolitischen Befund, der selbstverständlich geheimgehalten wurde, in verschiedene Lager ein: in Siedlungslager die O-Fälle, die darauf warteten, daß fremde Höfe „freigemacht" wurden, auf denen sie angesetzt werden sollten; in Durchschleusungs- oder einfach Schleusungslager die A-Fälle auf ihrem Weg ins Altreich; in Beobachtungslager im Generalgouvernement die S- und kritischen Fälle" ${ }^{77}$.

Die Vielfalt der neuen Arbeitsbereiche beim RFSS RKF machte Kompetenzsicherungen bzw. -abgrenzungen nötig. Zunächst hielt es Himmler für wichtig, die noch immer formell dem Auswärtigen Amt angegliederte Volksdeutsche Mittelstelle auch äußerlich vom Auswärtigen Amt zu trennen. Ein Führererlaß vom 7.Dezember 1940 ordnete die Übertragung der bisher bei der Vomi ruhenden Vollmachten auf den Reichsführer SS an. Das Weisungsrecht in allen außenpolitischen Volkstumsfragen blieb, wie im Führererlaß vom 2. Juli 1938 festgelegt, beim Reichsminister des Auswärtigen, Himmler erhielt das Weisungsrecht in allen Volkstumsfragen „weltanschaulicher und sonstiger Art" ${ }^{\text {"78 }}$. Spätestens nach Ausbruch des Krieges mit der

\footnotetext{
76. Tagesbefehl Nr.468 vom 7.4. 1941, Geheim. Nur für die Lagerführer, GR T 81, R 268, F 2387520.

77 Diese Lager-Typen sind genannt in GR T 81, R 266, F 2384175.

78 „Vereinbarung über die Zuständigkeit in Volkstumsfragen“ zwischen dem. Reichsminister des
} 
UdSSR hatte das Auswärtige Amt somit jedes Mitspracherecht in den Angelegenheiten der Deutschen in der Sowjetunion verloren.

Mit Beginn des Rußlandfeldzuges und damit der praktischen Arbeit vor Ort wurde eine Reihe von internen Kompetenzabgrenzungen festgelegt, die vor allem das Ziel hatten, die unmäßigen Reibereien zwischen den Dienststellen Lorenz' im Rahmen der SS und Greifelts im Rahmen des RKF zu verringern.

Zunächst hatte es Lorenz in einem letzten Schlag gegen den Volksbund für das Deutschtum im Ausland verstanden, dessen Hauptabteilung „Hauptstelle für völkische Schutzarbeit" aus dem Verband herauszulösen und der Vomi unter dem Namen „Volksdeutsche Mittelstelle, Hauptstelle für völkische Schutzarbeit“ anzugliedern. Er hatte dabei einfach den zur Wehrmacht eingezogenen Leiter der Stelle, Adolf Frasch, durch SS-Obersturmführer O. Weber (Stellvertreter: Pg. Prof. Karl Schöpke) ersetzt und die Stelle einer „Neuordnung“ unterzogen. Sie trug von nun an die Verantwortung für alle im Reich sich aufhaltenden Volksdeutschen, Fremdvölkischen (einschließlich der andersethnischen Ehepartner von Volksdeutschen) und Ostarbeiter. Die Aufgaben der Dienststelle bestanden in „Kameradschaftsarbeit“, d.h. der Zusammenfassung volksdeutscher Gruppen zum Zwecke „volkspolitischer Arbeit“, in der „volkspolitischen Betreuung aller Volksdeutschen im Reich“ und in der „Beobachtung der Fremdvölkischen mit dem Ziele der Sicherung unseres Volkstums" "79.

Schließlich gab Himmler in seiner Eigenschaft als Reichsführer SS am 28.11. 1941 eine Anordnung über die Volkstumsarbeit heraus, welche die Kompetenzen der ihm unterstellen Vomi und des Stabshauptamtes des RKF untereinander und die Zuständigkeiten beider von den Aufgabenbereichen der NSDAP abgrenzte - eine weitgehende Entmachtung der Volkstumsspezialisten der NSDAP, deren Arbeit als zu theoretisch galt, zugunsten der „aktiv durchgreifenden“ Himmler-Dienststellen ${ }^{80}$. Diese Anordnung über den „Aufbau der Volkstumsarbeit der NSDAP und die Abgrenzung der Zuständigkeiten der Hauptämter der SS“ bestätigte die Zuständigkeit der Vomi für die gesamte Führung der volksdeutschen Arbeit im Reich und in den unter deutscher Oberhoheit stehenden Gebieten. Sie beauftragte die Vomi mit der Durchführung der Maßnahmen zur Aufnahme wiedereindeutschungsfähiger Personen (Volksliste, Abt. 3) und der eindeutschungsfähigen Fremdvölkischen in die deutsche Volksgemeinschaft. Der Vomi wurde ferner der gesamte Komplex der Aussiedlung der Volksdeutschen aus ihren bisherigen Wohngebieten übertragen. Die Aufgabe umschloß die Planung, Vorbereitung und vertragliche Regelung der vom Reichsführer SS angeordneten Umsiedlung; allerdings sollte Lorenz in diesen Fragen das Stabshauptamt Greifelts hinzuziehen. Dies galt ebenso für die Vermögensfragen der

Auswärtigen, Ribbentrop, und dem RKF Himmler, Berlin, 31. März 1941, AA Inl. II C, D VIII, Akten betreffend: Volksdeutsche Mittelstelle, Bd. 5 (1941-44) Nr. 2, D 526466.

79 GR T 81, R 266, F 2384161.

$80 \mathrm{Vgl}$. Der Reichsführer SS Reichskommissar für die Festigung deutschen Volkstums, „Abgrenzung der Aufgaben zwischen dem Hauptamt Volksdeutsche Mittelstelle und dem Stabshauptamt“, 9. IX, 1942, AA Inl. II C, D VIII, Akten betreffend: Volksdeutsche Mittelstelle, Bd. 5 (1941-44), Nr.2, D 526468-70. 
Umsiedler. Mit der Aussiedlung war die Frage des Transports und der Unterbringung in Lagern verbunden. Für die Leitung aller volksdeutschen Lager war ebenfalls die Vomi zuständig; sie führte die propagandistische „Betreuung“ der Lagerinsassen durch, entschied über die Art ihres Arbeitseinsatzes und nahm, wiederum unter beratender Heranziehung des Stabshauptamtes, „die Ausrichtung der Siedler auf ihre späteren Aufgaben im Ansiedlungsgebiet" vor. Das Stabshauptamt Greifelts erhielt die Zuständigkeit über „die gesamte Siedlungs- und Aufbauplanung und deren Verwirklichung“ im Reich und in den besetzten Gebieten, für „die kulturelle und verwaltungsmäßige Planung und die Propaganda für den Siedlungsgedanken“, für alle Fragen des „Menscheneinsatzes“ in den Siedlungsgebieten und für die „im Rahmen der Umsiedlungsaktion anfallenden wirtschaftlichen Fragen", vor allem die Fragen des geplanten, aber nur in wenigen Fällen durchgeführten Vermögensausgleiches der Umsiedler. Bezüglich der Siedlung oblag dem Stabshauptamt ferner die Einsetzung und Führung der Ansiedlungsstäbe, die Durchführung der Ansiedlung und die endgültige Arbeitsvermittlung aller Umsiedler, die Beschaffung von Wohnungen, Unterkünften und Möbeln für die Umsiedler usw.

Im Hinblick auf die Fragen der Eindeutschung und Wiedereindeutschung (WED) sollte die Vomi die „Richtlinien für die Inarbeitbringung der Eindeutschungsfähigen [geben] und ... deren politische und soziale Betreuung" durchführen. Im Rahmen der „Festigung deutschen Volkstums“ in den neuen Reichsgebieten, den eingegliederten und besetzten Gebieten, war die Vomi zuständig für die Erfassung des Deutschtums, seine politische Führung und soziale Betreuung; diese Aufgaben bezogen sich auch auf die Angehörigen der Abteilung 3 und 4 der Deutschen Volksliste. Das Stabshauptamt hingegen sollte den Arbeitseinsatz und die Ansiedlung leiten und die wirtschaftlichen Fragen des Vermögensausgleiches lösen.

Es war offenkundig, daß diese Kompetenzabgrenzung in der Praxis mehr Verwirrung stiften mußte, als sie Reibungen und Streitfälle beheben konnte. Zwischen den Dienststellen Lorenz' und Greifelts schwelte ein permanenter Kampf ${ }^{81}$. Hinzu kam, daß auch zahlreiche andere Dienststellen diese Kompetenzverteilung mit Argwohn verfolgten; so lag z.B. die Frage des Vermögensausgleiches der Umsiedler und der Zuweisung von gleichwertigen Immobilien in den Händen der 1939 gegründeten Deutschen Umsiedlungs-Treuhand $\mathrm{GmbH}^{82}$; sie wurde nunmehr auch offiziell zu einer mit beiden Stäben konkurrierenden Stelle. Allerdings hatte sich SS-Oberführer im Persönlichen Stab des Reichsführers SS, Ulrich Greifelt, bei ihrer Gründung die Position des Stellvertreters des Vorsitzenden (Staatssekretär z.b.V. Wilhelm Keppler) und damit einen mitbestimmenden Einfluß gesichert. Das Reichssicherheitshauptamt der SS hatte Mitspracherecht in den Fragen der (Wieder-)Eindeutschung. Daß der Oberste Prüfungshof der Deutschen Volksliste Greifelts Stabshauptamt unterstand

81 Vgl. die Zurechtweisungen und Schlichtungsversuche an die Adresse Lorenz' und Greifelts im Brief Reichsführer SS an Lorenz vom 4.12. 1942, Feldkommandostelle, Tgb.Nr. 30/4/43 g, GR T 175, R 68, F 2585149.

82 Gründung der Deutschen Umsiedlungs-Treuhand G.m.b.H. (DUT) am 11. Nov. 1939, vgl. Pressemitteilung, GR T 81, R 272, F 2391845. 
und an ihm nun auch die Vomi beteiligt wurde ${ }^{83}$, machte die Prüfung dieser Fälle nicht weniger kompliziert. - In der Praxis regelte die Vomi bei der „Erfassung“ der Volksdeutschen oft auch die Fragen des wirtschaftlichen Ausgleichs oder der Zuteilung von Wohnraum; sie requirierte jüdische und andere Immobilien, „beseitigte“ ihre Eigentümer und wies den Besitz den ortsansässigen Deutschen zu. Auch machte die Vomi von ihrer Macht in den Umsiedlungs- und Schleusungslagern, die bis zur unbeschränkten Disziplinargewalt und zum Recht auf körperliche Züchtigung reichte, unbeschränkten Gebrauch. Dieses Netz ineinander übergreifender Kompetenzen war geeignet, die robustesten und machtbesessensten Elemente in diesen Organen zu rücksichtsloser Durchsetzung ihrer eigenen Ziele auf Kosten der mit ihnen konkurrierenden Ämter und Personen zu verleiten. Die Leidtragenden der ämterinternen Kämpfe um maximalen Machtgebrauch waren als schwächste Glieder der Maschinerie die Volksdeutschen.

Die Dienststellen Himmlers waren auch federführend bei der Ausarbeitung des umfassenden Siedlungsplanes für die eroberten Gebiete Osteuropas, des „Generalplan

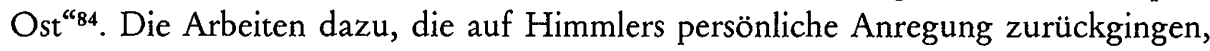
setzten vermutlich im Januar 1940 ein $^{85}$. Ausführende Organe waren das Reichssicherheitshauptamt der SS und das Stabshauptamt des RKF. Die Beschäftigung mit dem Plan reichte bis weit in die Zeit des Rußlandfeldzugs hinein. Der Generalplan Ost sah die Germanisierung des Ostraums durch deutsche Kolonisation vor. Sein Nahziel („Nahplan") war die Eindeutschung der eingegliederten Ostgebiete, sein Fernziel („Fernplan“) die Germanisierung großer Teile der besetzten UdSSR.

Himmler selbst hatte am 24.6. 1940 einen siedlungspolitischen Versuch zu Papier gebracht, der Hitlers volle Zustimmung gefunden hatte ${ }^{86}$. Er folgte darin den Ideen, die Hitler in Mein Kampf entwickelt hatte, und suchte nach einer Form der konkreten Anwendung für die besetzten Gebiete Osteuropas. Deutsch, so war seine These, seien Länder und Provinzen nur dann, „wenn sie grundsätzlich bis zum letzten Mann und bis zur letzten Frau ... deutsch besiedelt werden und sind“. Die „Deutschwerdung eines Landes“ werde also dann erreicht, wenn „das Land in einem genügenden Umfang mit geeigneten deutschen und germanischen Bauern besiedelt" sei, daher sollten Millionen deutscher Siedler in den besetzten Ostraum geführt werden. In das durch Besiedlung zu germanisierende Land sollten auch Güter eingestreut werden - ein Versprechen an besitzhungrige SS-Veteranen, das Himmler in großzügigstem Maße hielt. Die leitenden Positionen dieser Güter sowie alle festen Stellen sollten von deutschen bzw. germanischen Kräften besetzt werden. Für niedere Arbeiten kämen slawische Wanderarbeiter in Frage. Diese fremde Bevölkerung sollte im Prozeß der Besiedlung noch „in größerem Maßstab“ eingesetzt werden, aber nach Erledigung die-

83 „Abgrenzung ...“, 9.IX. 1942, S. 3 (s. Anm. 80).

$84 \mathrm{Vgl}$. Heiber, H., Der Generalplan Ost, in VfZ 6 (1958), S. 281-325, sowie ergänzender Hinweis zum Textbestand in: VfZ 8 (1960), S.119; GR T 175, R 68, F 2585083-95, Nbg. Dok. NO-2255.

${ }_{85} \mathrm{Vgl}$. Nbg. Dok. NO-2275.

${ }^{86}$ Aufzeichnungen Himmlers über die zukünftigen deutschen Bauernsiedlungen. Unsignierte Aufzeichnung im BA NS 19/184; Abdruck in: Ackermann, Himmler, S. 300-303. 
ser Arbeiten Zug um Zug „ausgesiedelt“ werden. „Ein heiliges, für alle Zeiten gültiges Gesetz bei der Verwendung dieser fremdrassigen Wanderarbeiter muß sein:

1. Unmöglich und verboten ist jede wirtschaftliche Gleichstellung mit germanischen Menschen,

2. unmöglich und verboten ist jede gesellschaftliche Gleichstellung,

3. unmöglich und verboten ist jede geschlechtliche Vermischung zwischen diesen fremdrassischen und germanischen Menschen."

In diesem „Grundgesetz" der Siedlung sah Himmler - im Unterschied zu seinen sonst allzu offenkundigen alldeutschen Vorbildern - „den Sozialismus des deutschen Blutes". Wer immer von deutscher Seite gegen dieses Grundgesetz verstoßen würde, sollte schärfsten Strafen bis hin zur Todesstrafe verfallen. Verstöße von seiten Fremdrassischer standen schon zu dieser Zeit unter schärfsten Strafen: „Der Fremdrassische, der eine deutsche Frau oder ein deutsches Mädchen verführt, verfällt dem Strang. Deutsche Männer und Frauen, die sich mit Fremdrassischen, und fremdrassische Frauen, die sich mit deutschen Männern einlassen, kommen ins Konzentrationslager."

Im Frühjahr 1941 beauftragte Himmler den Direktor des Instituts für Agrarwesen und Agrarpolitik der Universität Berlin, Prof. Dr. Konrad Meyer, mit der Ausarbeitung eines detaillierten Plans zur Besiedelung des Ostens. Die erste Fassung des Generalplans Ost, die Meyer Himmler am 15.7. 1941 vorlegte, war weitgehend vor Beginn des Rußlandfeldzuges entstanden und hatte den russischen Raum noch nicht eingeschlossen. Während eines Vortrags Meyers vor Himmler (27.1. 1942) erteilte ihm dieser den Auftrag, in einem zweiten detaillierten Siedlungsplan auch den russischen Raum einzubeziehen. Die zweite Fassung Meyers, „Generalplan Ost - Rechtliche, wirtschaftliche und räumliche Grundlagen des Ostaufbaus", vorgelegt am 28. Mai 1942, setzte für die Eindeutschung der Ostgebiete einschließlich der Siedlungsmarken Ingermanland (Petersburger Gebiet), Gotengau (Krim und Chersongebiet), Memel- und Narewgebiet (Bezirke Bialystok und Westlitauen) und weiterer 36 Siedlungsstützpunkte einen Zeitraum von 25 Jahren, aufgeteilt in fünf Fünfjahrespläne, an. Die genannten Siedlungsmarken sollten zu 50\%, die Stützpunkte zu 25-30\% eingedeutscht werden. Die „Siedlerbilanz" dieses Plans sah vor, zur Eindeutschung der Marken und Stützpunkte in den besetzten Gebieten 3,35 Millionen Siedler zu verwenden: deutsche Siedler aus dem Altreich, Umsiedler aus Übersee (in erster Linie Deutsche aus den USA), germanische Siedler aus Europa, Eindeutschungsfähige aus den besetzten Ostgebieten und Volksdeutsche aus der UdSSR ${ }^{87}$. Der Plan ging von 100000 deutschen Familien in der Sowjetunion mit durchschnittlich vier Kindern, d.h. einer Gesamtzahl von 600000 russischen Deutschen aus; diese sollten innerhalb der besetzten Gebiete aus den Ballungszentren ihrer Siedlungen im DnjeprBogen und ehemaligen Taurien in die Zonen der geplanten Eindeutschung umgesiedelt werden.

${ }^{87}$ Dies geht aus der Stellungnahme von Dr. E. Wetzel zu diesem Plan hervor; vgl. Heiber, Generalplan, S. $298 \mathrm{ff}$. 
Himmer gefiel, wie er Greifelt in einem kritischen Kommentar mitteilte, der Entwurf „ganz gut" ${ }^{\text {"88; }}$ nur glaubte er, in einigen Fragen mißverstanden worden zu sein: Er ging von der Eindeutschung dieser Gebiete „im Laufe von möglichst 20 Jahren“ aus, und im Rahmen dieses Zwanzigjahresplanes sollte die "totale Eindeutschung von Estland und Lettland sowie des gesamten Generalgouvernements" stattfinden. Die Anlage von Stützpunkten germanischer Besiedlung genüge nicht.

Am 23. Dezember 1942 legte Meyer eine neue Zusammenstellung von Grundzahlen und Karten für einen Generalsiedlungsplan vor ${ }^{89}$. Himmler kommentierte sie mit den Worten: „In den Ostsiedlungsraum ist Litauen, Lettland, Estland, Weißruthenien und Ingermanland ebenso wie die ganze Krim und Taurien einzubeziehen ... N. B. Diese genannten Gebiete müssen total eingedeutscht bzw. total besiedelt werden. ${ }^{"}{ }^{\circ 0}$ Meyer wurde zu einer weiteren Umarbeitung des Generalsiedlungsplanes in diesem Sinne veranlaßt. Doch schon am folgenden Tag ordnete ein Erlaß Hitlers die Einstellung aller laufenden Planungen und Vorbereitungen und ihre Vertagung auf Kriegsende $a^{91}$.

In die Vorarbeiten zum Generalplan Ost versuchten sich mit Beginn des Rußlandfeldzuges auch andere Instanzen einzuschalten. Am 17. Juli 1941 war Alfred Rosenberg zum Reichsminister für die besetzten Ostgebiete ernannt worden ${ }^{92}$. In sein Ministerium, dessen Schlüsselpositionen er mit Angehörigen seines Stabs aus dem Außenpolitischen Amt der NSDAP besetzte, wurden bald auch Verbindungsleute aus und zu anderen Dienststellen abgestellt, die sich aus dem allzu großen Amtsbereich Rosenbergs ihren Teil herausschneiden und sichern wollten. Als Verbindungsmann des Rassenpolitischen Amtes der NSDAP mit engen, wenn auch undurchsichtigen Beziehungen zum Reichssicherheitshauptamt der SS zog Dr.Erhard Wetzel in das OstMinisterium ein. Hier wurde er nach einigem Wandern durch die Abteilungen Leiter des für ihn geschaffenen Sonderdezernats Ie Rassenpolitik. In dieser Eigenschaft legte Wetzel am 27.4. 1942 seine „Stellungnahme und Gedanken zum Generalplan Ost des Reichsführers SS“ vor ${ }^{93}$. Wetzel äußerte Zweifel daran, daß sich die Gesamtzahl von zehn Millionen germanischer Siedler, welche der Generalplan Ost vorsah, in dem geplanten Zeitraum (von Wetzel irrtümlich auf 30 Jahre veranschlagt) erreichen lassen würde, und ging von acht Millionen aus. Andererseits hoffte er, daß in der So-

${ }^{88}$ Reichsführer SS, Tgb.Nr. AR/33/11/42, Führer-Hauptquartier, 12. Juni 1942, GR T 175, R 68, F $2585091 \mathrm{f}$.

89 Vgl. Begleitschreiben von SS-Gruppenführer Greifelt, Stabshauptamt des RKF, VI-1/373/42, Tgb.Nr.118/42, GR T 175, R 68, F 2585093.

90 Der Reichsführer SS, Tgb.Nr. 47/20/43 g, Feld-Kommando-Stelle, 12. Januar 1943, GR T 175, R 68, F 2585094.

91 Erwähnt im Runderlaß des Reichsministers des Innern vom 6.4. 1943; vgl. Heiber, Generalplan, S. 292.

92 Erlaß des Führers über die Verwaltung der neu besetzten Ostgebiete vom 17. Juli 1941, in: Der Reichsminister für die besetzten Ostgebiete, III, Wi 2461/42. Die Zivilverwaltung in den besetzten Ostgebieten (Braune Mappe). Teil A. Richtlinien für die Wirtschaftsführung, Berlin, April 1942, S. $40 \mathrm{f}$.

${ }_{93}$ Nbg. Dok. NG-2325, Abdruck in: Heiber, Generalplan, S. $297 \mathrm{ff}$. 
wjetunion „eine weitaus größere Menge der Volksdeutschen“ gerettet und für das Siedlungswerk verwendet werden könnte. Er nahm ferner an, daß die Zahl der Fremdvölkischen, die aus diesem künftigen germanischen Siedlungsraum „evakuiert“ werden sollten, nicht - wie im Generalplan Ost angegeben - bei 45 Millionen, sondern bei 51 Millionen liege: nämlich ca. 45 Millionen Fremdvölkische, vor allem Slawen, plus „,5 bis 6 Millionen Juden, die ... schon vor der Evakuierung beseitigt“ werden müßten ${ }^{94}$. In ihre Siedlungsräume sollten dann sowohl deutsche Siedler aus dem Altreich, wenn möglich ohne Anwendung von Gewalt, als auch volksdeutsche Umsiedler aus anderen Teilen der Sowjetunion eingewiesen werden. Hierbei entstehe freilich die Frage, „ob die Volksdeutschen, die in der Ukraine oder der Krim wohnen, dort weiter verbleiben und ob evtl. die Volksdeutschen aus anderen Gebieten der Sowjetunion gleichfalls in diese Gebiete geschafft werden sollen. Der Generalplan Ost sieht die Rücksiedlung aller dieser Deutschen in den von ihm angenommenen Siedlungsräumen vor. Wenn auch die volkspolitischen Gesichtspunkte eine Umsiedlung dieser Volksdeutschen befürworten dürften, sprechen andererseits schwerwiegende wirtschaftliche Gesichtspunkte dagegen, weil ja bekanntlich der Reichtum der Ukraine sich in erster Linie auf die Arbeitskräfte dieser Deutschen stützte. " ${ }^{\text {"95 }}$ Ein den Einsatz dieser Deutschen erschwerendes Element sah Wetzel in der Fraglichkeit ihrer rassischen Eignung ${ }^{96}$. Anthropologische Untersuchungen an Deutschen aus Bessarabien (1938) hätten gezeigt, daß es - bei gleichbleibenden Schädel-Indices - zu klimabedingten Veränderungen der Haarfarbe gekommen sei. Eine Dauersiedlung in einigen südrussischen Gebieten empfehle sich daher aus Gründen der Rassenreinhaltung nicht. Allgemein gab Wetzel zu bedenken, ob die rassenpolitischen Prüfungsmethoden des Rasse- und Siedlungshauptamtes, die als SS-Maßstäbe eine „Auslese des deutschen Volkes“ schaffen sollten, für die Beurteilung dieser Menschen geeignet seien.

Wetzels rassenpolitische Überlegungen zur Siedlerfrage wichen freilich von den Betrachtungen $\mathrm{ab}$, die sonst im Reichsministerium für die besetzten Ostgebiete angestellt wurden. Schon einige Monate vor Beginn des Rußlandfeldzuges und der Ernennung zum Reichsminister Ost hatte Rosenberg begonnen, Pläne für die „Befriedung“ des Riesenreiches im Osten zu erstellen. Hitler hatte den in seinen Augen mit dem russischen Raum vertrauten Rosenberg beauftragt, Denkschriften zu diesen Fragen auszuarbeiten und ihm in gelegentlichen persönlichen Vorträgen Mitteilung zum Stand seiner Planungsarbeiten für den Ostraum zu machen"7.

94 Heiber, Generalplan, S. 300.

${ }_{95}$ Ebenda, S. $322 \mathrm{f}$.

96 Diese Frage hatte die rassenpolitischen Spezialisten verschiedener Ämter seit 1933 beschäftigt; vgl. u.a. Keiter, W., Anthropologisches Institut der Universität Kiel. Rußlanddeutsche Bauern und ihre Stammesgenossen in Deutschland. Untersuchungen zur speziellen und allgemeinen Rassenkunde, Jena 1934.

97 Vgl. die Nachzeichnung des Vortrags vom 9. Mai 1941 in: Thorwald, J., Wen sie verderben wollen. Bericht des großen Verrats, Stuttgart 1953, S.19ff. Material Thorwalds zu diesem Buch im Archiv des IfZ, Bestand ZS/A 3; die Informationen zu den hier interessierenden Fragen stammen 
Wie seine Lehrmeister aus dem alldeutschen Lager und den Rängen der frühen Münchener NSDAP ging Rosenberg von der Annahme aus, Rußland sei in erster Linie als ein aus verschiedenen Völkerschaften zusammengesetztes Konglomerat zu verstehen, das beim ersten wohlplazierten militärischen Schlag zusammenbrechen und eine „außerordentlich schnelle Okkupation“ erlauben werde ${ }^{98}$. In diesem militärischen Schwächezustand müsse dann die „politische Zertrümmerung des östlichen Großreiches“ vorgenommen werden. Zu diesem Zwecke müsse die Besetzung „ungeheuer große Gebiete umfassen". Dies seien naturgemäß die nationalen und geographischen Einheiten eines stark zu verkleinernden Großrußland mit Zentrum Moskau, Weißrußlands mit Hauptstadt Minsk bzw. Smolensk, der baltischen Provinzen Estland, Lettland und Litauen, der Ukraine mit der Krim und Zentrum Kiew, des Dongebiets mit der Hauptstadt Rostow, des Kaukasusgebiets und Russisch-Mittelasiens bzw. Russisch-Turkestans.

Rosenbergs Plan sah vor, das gesamte Großrussentum auf ein russisches Kernland (Großrußland als ein Rest- oder Rumpf-Rußland) zurückzudrängen, das zugleich "als Abschubgebiet für unerwünschte Elemente in größerem Ausmaß zu benutzen“" sei. Es sollte durch eine militärische Niederlage zunächst so stark geschwächt werden, daß es sich niemals wieder zu einem regierungsfähigen Land entwickeln würde. Weißrußland war die Rolle eines diesem Rumpfgebilde vorgelagerten Pufferstaates zugedacht. Dementsprechend sollte es weit nach Osten, bis etwa $250 \mathrm{~km}$ vor Moskau, ausgedehnt werden und das frühere Twer (Kalinin) mit einschließen. Bisher kulturell und wirtschaftlich zurückgeblieben und "das zweite Judenreservoir der UdSSR“, sollte Weißrußland laut Plan von seinen „ethnisch unerwünschten“ Massen gesäubert und zu einem „Eigenleben“ erweckt werden.

Das Siedlungsgebiet der Zukunft sollte für das Deutsche Reich zunächst das Baltenland, also Estland, Lettland und Litauen, sein. Die rassisch geeigneten Elemente dieser Provinzen sollten durch Assimilation für die deutsche Siedlungsaufgabe verwendbar gemacht werden; größere Intelligenzschichten, besonders aus der lettischen Bevölkerung, und rassisch minderwertige „größere Bevölkerungsgruppen“ aus Litauen sollten ins russische Kernland „abgeschoben“ werden. „Die Ansiedlung einer mengenmäßig bedeutenden deutschen Landbevölkerung müßte in Angriff genommen werden, evtl. könnte ein großes Kontingent dafür geeigneter deutscher Siedler aus den Wolgadeutschen - nach Ausscheiden der unerwünschten Elemente - entnommen werden. In Frage käme aber auch die Ansiedlung von Dänen, Norwegern, Holländern und - nach siegreicher Beendigung des Krieges - auch von Engländern, um im Laufe einer oder zweier Generationen dieses Gebiet als neues eingedeutschtes Land dem deutschen Kernland anschließen zu können."

In Hinblick auf die Ukraine sah es Rosenberg als politisches Ziel an, das nationale Eigenleben bis zur eventuellen Errichtung einer Eigenstaatlichkeit zu fördern; Aufgabe

aus ZS/A 3 - O. Bräutigam (5), Eugen Dürksen (7), Hans v. Herwarth (18), Ernst Köstring (24), Gerh. v. Mende (29) und A. von der Milwe (307).

${ }_{98}$ Rosenberg, „1.Denkschrift. Betrifft: UdSSR“, 2.4. 1941, Nbg. Dok. PS-1017. 
des Ukrainestaates sollte es sein, „allein oder in Verbindung mit dem Dongebiet und dem Kaukasus als Schwarzmeerbund Moskau stets im Schach zu halten und den großdeutschen Lebensraum vom Osten her zu sichern“. Zur Stärkung des Pufferstaates Ukraine, der zudem eine „ständige Rohstoff- und Ernährungsbasis für das Großdeutsche Reich" bilden sollte, wollte Rosenberg der Ukraine im Osten noch einen breiten "Grenzstreifen aus dem russischen Kerngebiet", nämlich die innerrussischen Gebiete von Kursk und Woronesch, zuschlagen.

Das Dongebiet, für dessen kosakische und traditionellerweise auf Moskau ausgerichtete Bevölkerung Rosenberg spezifische „Befriedungsprobleme“ voraussetzte, sollte nach Norden hin eine Ausdehung bis zum Verwaltungsbezirk Saratow erfahren, „um den verwaltungsmäßigen Anschluß an das Gebiet der Wolgadeutschen herzustellen“. Im Kaukasus, dem Ölzentrum Rußlands, sollte im Hinblick auf die Instandhaltung der Wirtschaft gegenüber der örtlichen, moskaufeindlichen Bevölkerung eine besonders nachsichtige, jede Unruhe vermeidende Politik angewandt werden. Die Versorgung des Wirtschaftszentrums hätten die weithin agrarischen Gebiete der besetzten Sowjetunion, nämlich die Ukraine, das Don-Kuban- und das Terek-Gebiet, zu übernehmen.

Sei der Sowjetstaat erst zusammengebrochen, so werde die deutsche Armee mit Leichtigkeit die mittelasiatischen Gebiete, die „Baumwollkammern“ des Reiches, einnehmen und von dort her eine Stärkung Afghanistans und des Iran gegen Indien betreiben können.

Diese erste Denkschrift Rosenbergs kam Hitlers Wünschen aus einer Reihe von Gründen nicht entgegen, was Rosenberg veranlaßte, innerhalb von fünf Tagen eine weitere auszuarbeiten". Rosenbergs „Denkschrift Nr.2“ ging ebenfalls von der Voraussetzung aus, daß Rußland „kein einheitlicher Staat mit einem alles beherrschenden Staatsvolk, sondern zweifellos ein Nationalitätenstaat" sei, war aber in der Verteilung gewisser Freiheiten an einzelne dieser Nationen schon weniger generös und rekurrierte stärker auf die "angestammten deutschen Siedlungsrechte“ in den verschiedenen Gebieten Rußlands.

Zunächst sah die Denkschrift die Vereinigung der Ostseeprovinzen mit Weißruthenien (Weißrußland) in einem Protektorat vor, das eng an das Großdeutsche Reich angeschlossen würde. „Einen historischen und augenblicklichen politischen Rechtsanspruch" habe das Deutsche Reich auf den Grund- und Immobilienbesitz, den die deutsche Oberschicht als „Ergebnis einer vielhundertjährigen Arbeit des deutschen Volkstums" in diesen Gebieten vor Vertreibung und Enteignung besessen habe. Dieser Besitz sei in seiner Gesamtheit, einer Fläche von der Größe Ostpreußens, „als deutsches Nationaleigentum ... großdeutsch und unabhängig von den individuellen Besitzern, die früher auf diesen Gütern gesessen haben“, zu betrachten. Ohnehin habe der baltische Adel 1918 „dem Deutschen Reich ein Drittel seines Gesamtbesitzes angeboten ..., ohne später die Möglichkeit zu erhalten, dieses Versprechen durchzuführen“. Nun sah es der deutschbaltische Kleinbürger Rosenberg bei seiner nachträg-

99 Rosenberg, „Denkschrift Nr. 2. Streng geheim. Betrifft: UdSSR“, Nbg. Dok. PS-1018. 
lichen faktischen Enteignung des baltischen Adelslandes nur als allzu berechtigt an, dieses „deutsche Nationaleigentum einer zunächst deutschen, dann aber vielleicht germanischen Kolonisation" $\mathrm{zu}$ unterziehen. Vorberechtigt für Besitznahme in diesem Gebiet sollten Baltikumkämpfer (Freikorps-Männer von 1918/19) und ihre Nachkommen, dekorierte Frontsoldaten und Balten mit Kriegsauszeichnungen sein. „Schließlich eventuell die Wolgadeutschen und Kaukasusdeutschen, deren hoffentlich eine große Zahl auf die Ostseeprovinzen und auf das Wartheland verteilt werden kann. Die politische Zielsetzung wird dann darauf hinauslaufen müssen, dieses deutsche Besiedlungsgebiet möglichst geschlossen zu halten und für Esten, Letten und Litauer besondere Umsiedlungsbestimmungen und ... Aussiedlungsbestimmungen zu treffen." Rosenberg sah die Abschiebung rassisch oder sonst unwillkommener Elemente in das Gebiet östlich des Peipussees vor. Die Grenze dieses geplanten OstseeProtektorats sollte nicht auf der historischen Linie Narwa-Peipussee, sondern „weiter in Richtung Petersburg"verlaufen.

In der Ukraine sollte - nach dem Wunsche Rosenbergs noch immer - „die Errichtung eines selbständigen ukrainischen Staates mit allen Konsequenzen angestrebt werden, der in einem engen Bündnis mit dem Deutschen Reich steht“.

Für Don- und Wolgagebiet sah Rosenberg aufgrund des dort vorhandenen „starken Einschlags des Großrussentums" eine wesentlich "härtere"Verwaltung vor als in den anderen Gebieten. Er hielt es für wahrscheinlich, daß Deutschland im Don- und Wolgagebiet ein Gegner erwachsen werde, der erst später „durch eine Erweiterung der Ukraine und des Kaukasus eingeengt und ausgeschaltet werden“ könne. „Da es für die militärische Okkupation gegebenenfalls notwendig erscheint, die Wolgalinie zu beherrschen, ergibt sich auch die Notwendigkeit, auf das deutsche Volkstum im Wolgagebiet zu achten. Es betrug früher nahezu 2 Millionen, ist in der Zeit seit 1914 aber zum Teil enteignet, verjagt und zum Teil auch ausgerottet worden. Heute rechnet man mit etwa 6 bis 700000 Menschen. Ob diese gerettet werden können, vermag heute niemand zu wissen; jedoch ist dies ein derartig vorgeschobener Posten, daß er auf die Dauer nicht zu halten sein wird und es wäre deshalb schon heute zu überlegen, ob man diese ganze Gruppe, die aus erstklassigen deutschen Siedlern (Schwaben) besteht, geschlossen irgendwo in der Ukraine ansiedelt oder im Wartheland und in den Ostseeprovinzen."

Rosenbergs Ausführungen über die Deutschen des Wolgagebiets waren ein wirres Gemisch von Fehlern: 1914 hatten über zwei Millionen Deutsche im gesamten Zarenreiche gelebt, von ihnen etwa $550000 \mathrm{im}$ Wolgagebiet. Um das Jahr 1941 war in Deutschland bekannt, daß in der UdSSR etwa 1,4 Millionen Deutsche, von ihnen etwa $400000 \mathrm{im}$ Wolgagebiet lebten ${ }^{100}$. Offenbar wirkte in Rosenberg trotz gelegentlicher Belehrungen durch seinen Amtsleiter Osten, jetzt Chef der Hauptabteilung I,

100 Ende der dreißiger Jahre bewegten sich die deutschen Schätzungen in der pessimistischen Tiefe von ca. 900000 Deutschen in der Sowjetunion (Mergenthaler, A., Rußlanddeutschtum in Zahlen, Leipzig 1940) oder 6-800000 im europäischen Rußland (vgl. Vorlage bei der Kulturabteilung des Auswärtigen Amtes, A 4223, Herrn VLR Lorenz, 10. Oktober 1939, AA, Inl. II C, Akten betreffend: Förderung des Deutschtums in Rußland, Bd. 4 [1937-44], Nr.1, D 626182). Doch die so- 
Politik im Reichsministerium Ost, Leibbrandt, die alte Unkenntnis der alldeutsch orientierten Deutschbalten über die deutschen Kolonisten fort. Dies hinderte ihn jedoch nicht, in ebenso pauschaler wie historisch und sachlich unrichtiger Art die Wiederherstellung des „deutschen Eigentums“ dieser Siedler zu fordern: „Was das deutsche Eigentum anbetrifft, so müßte der Ukraine, dem Kaukasus und dem Dongebiet das gleiche betont werden, wie den Ostseeprovinzen gegenüber. Die Siedler sind vom früheren russischen Reich gebeten worden, in diese Länder einzuziehen, und sie haben hier nicht etwa wucherisch gewirkt, sondern in Jahrhunderten die größte schöpferische Arbeit geleistet.“ Deshalb sei „das ehrlich erworbene Eigentum dieser Gebiete ... deutscher Volksbesitz gewesen und ... die nunmehr befreiten Länder und Völker“ hätten diesen Grundsatz anzuerkennen. „Der deutsche Grundbesitz in der Ukraine und im Wolga-Dongebiet (entsprach) etwa der Größe Württembergs.“

In seiner „Instruktion an einen Reichskommissar in der Ukraine" ${ }^{101}$ führte Rosenberg den nationalsozialistischen Grundsatz, nach dem „das in Jahrhunderten und Jahrzehnten erarbeitete Eigentum der Volksdeutschen ... Eigentum des deutschen Gesamtvolkes" sei, weiter aus. Die künftige selbständige Ukraine, so forderte er, müsse Deutschland für den Besitz der Volksdeutschen entschädigen. Die Art dieser Kompensation werde einer späteren Entscheidung vorbehalten bleiben. Doch biete sich die ohnehin in der Mehrzahl von anderen „Fremdvölkischen“ besiedelte Krim als Kompensationsobjekt an: „Große Gebiete der Krim gehörten schon vor dem Kriege den deutschen Kolonisten ... Der Grundbesitz der deutschen Kolonisten im Schwarzmeergebiet war größer als Württemberg, Baden und das Elsaß zusammen." Die Krim sei somit ein gerechtfertigter Preis für das Verlorene. „Wenn ferner das die Ukraine rettende Deutsche Reich das Hoheitsgebiet der Ukraine über den Siedlungsraum hinaus bis an die Wolga (aus grenzstrategischen Gründen) auszudehnen bereit ist, so ist die Forderung nach Taurien auch hier gerechtfertigt."

Die Forderung nach der Krim und dem historischen Taurien als Gebieten der „Eindeutschung" ging auf das Diktat Hitlers zurück, dem sich Rosenberg nur mit Unwillen fügte. Doch bald sollte Rosenberg zu noch größeren Zugeständnissen an Hitlers historisch-geographisch unbedarfte Ostraumwillkür und zu noch brutaleren Eingriffen in die Rechte der Völker bereit sein, als er sie hier mit seiner Art der Nationalisierung des früheren Besitzes des baltischen Adels und der Kolonisten für das eigene Volkstum plante.

Wenige Wochen nach Beginn des Krieges gegen die UdSSR, am 16.7. 1941, unterbreitete Hitler einem kleinen Stab aus Ministerien und Heeresleitung seine Rußland-

wjetische Bevölkerungszählung von 1939, die ca. 1,4 Millionen Deutsche verzeichnete, hatte bald Anlaß zu mehr Optimismus gegeben; vgl. Izvestija, Moskau, Nr.99, 29.4. 1940, Ergebnisse der Volkszählung vom 17.1. 1939. Am 29. Juni 1940 hatte Lorenz dem Reichsamtsleiter im APA der NSDAP, Leibbrandt, „für den Fall, daß die Angelegenheit dort noch nicht bekannt" sei, unter Hinweis auf den AdW vom 1.6. 1940 mitgeteilt, daß „nach der russischen Zählung vom 7.1. 1939 die Zahl der in Sowjetrußland zum Deutschtum sich bekennenden Personen 1,4 Millionen beträgt“. Auswärtiges Amt, Kulturabteilung A 2358/8.

101 Nbg. Dok. PS-1028, vom 7.5. 1941. 
pläne ${ }^{102}$. Wie in der vorausgegangenen Zeit, so fanden die potentiellen Opfer seines Angriffs auf die Sowjetunion, die Deutschen der UdSSR, auch jetzt bei ihm keine Beachtung. Doch hatten seine Gespräche mit Himmler über Siedlungsfragen und mit Rosenberg über die Aufteilung der UdSSR in Verwaltungseinheiten offenbar gewisse vage Raumvorstellungen in ihm entstehen lassen, die er nun in einer Alles-oderNichts-Nutzanwendung in politische Realität umzusetzen suchte. Hitlers Ausgangspunkt war wie der seiner alldeutschen Vorbilder die Idee, es komme darauf an, „den riesenhaften Kuchen handgerecht zu zerlegen, damit wir ihn erstens beherrschen, zweitens verwalten und drittens ausbeuten können“. Die Ostgebiete Europas seien für Deutschland lebenswichtig, ja wichtiger als die Kolonien, und sollten deshalb zu einem Garten Eden gemacht werden. Hitler zählte auf, welche Gebiete Rußlands er $\mathrm{zu}$ „deutschem Reichsgebiete“ zu machen beabsichtige. Das gesamte Balten-Land gehörte dazu. „Ebenso müsse die Krim mit einem erheblichen Hinterland (Gebiet nördlich der Krim) Reichsgebiet werden; das Hinterland müsse möglichst groß sein." Rosenberg meldete gegen diese Ausweitung des Reichs aus dem Schwarzmeerraum tief in die Ukraine hinein Bedenken an; doch fanden seine Vorschläge hinsichtlich einer größeren Ukraine und der Erweckung eines eigenen Geschichtsbewußtseins der Ukrainer auch auf dieser Sitzung im Führerhauptquartier keine Beachtung. Hitler legte weiter fest, daß die Krim „von allen Fremden geräumt und deutsch besiedelt werden“ müsse. Später sprach er sich wiederholt dafür aus, alle „Fremdvölkischen aus der Krim schnellstmöglich abzuschieben. Wohin, sei ihm ganz wurscht. Rußland sei groß genug ..." ${ }^{103}$. Weiter sah Hitler vor, daß ,auch die Wolga-Kolonie (sic) ... deutsches Reichsgebiet werden [müsse] ebenso das Gebiet um Baku; es müsse deutsche Konzession werden (Militär-Kolonie) “. Das Gebiet um Leningrad wurde von den mit Deutschland verbündeten Finnen beansprucht; „der Führer will Leningrad dem Erdboden gleichmachen lassen, um es dann den Finnen zu geben“. Hinsichtlich des westlichen Schwarzmeerbeckens kündigte Hitler bereits hier an, er beabsichtige, Rumänien „Bessarabien und Odessa nebst einem Streifen, der von Odessa in Nord-Nordwest führt", zu geben. Die Einwände Rosenbergs in Hinblick auf diese wirtschaftlich und strategisch wichtigen und zudem dicht von Deutschen besiedelten Gebiete entkräftete Hitler mit der Bemerkung, daß die neue Grenze „wenig außerhalb der alten rumänischen Grenze führe".

Als allgemeine Richtlinien des Rußlandfeldzuges formulierte Hitler die Forderung, daß die Bildung einer militärischen Macht westlich des Ural nie wieder in Frage kommen dürfe, „und wenn wir hundert Jahre darüber Krieg führen müßten“. Alle seine möglichen Nachfolger sollten wissen: „... die Sicherheit des Reiches ist nur dann gegeben, wenn westlich des Ural kein fremdes Militär existiere; den Schutz dieses Raumes vor allen eventuellen Gefahren übernimmt Deutschland." Eiserner Grundsatz sei deshalb: „Nie darf erlaubt werden, daß ein Anderer Waffen trägt, als der Deutsche!“

${ }^{102}$ Führerhauptquartier, 16.7.1941, Geheime Reichssache, Aktennotiz (Bormanns), Nbg. Dok. L-221; vgl. Kamenetsky, Occupation, S. 35 ff.

${ }_{103}$ Tagebuch von Etzdorf, Eintragung vom 12. August 1941, Nbg. Dok. NG-2775. 
Zur raschestmöglichen Befriedung dieses Riesenraumes stellte Hitler die Regel auf, „daß man Jeden, der nur schief schaue, totschieße". Alle Einwohner dieses Raumes müßten wissen, „daß jeder erschossen würde, der nicht funktioniere, und daß sie für jedes Vergehen haftbar gemacht würden“.

Als besonders zählebig von diesen Plänen Hitlers erwies sich der der Krim-Besiedelung ${ }^{104}$. Die kühnen Besiedlungspläne, welche die Himmler-Dienststellen, vor allem das Stabshauptamt Greifelts, schmiedeten, sahen in der Krim, nun Gotenland genannt, wechselweise den Ansiedlungsgrund für die auf 140000 Personen geschätzten Schwarzmeerdeutschen der an Rumänien fallenden Teile des Schwarzmeerbeckens (Transnistrien) ${ }^{105}$, für die deutsche Bevölkerungsgruppe Südtirols, etwa 200000 Optanten - ein Plan, der auf eine Anregung Hitlers aus dem Jahre 1940 zurückging ${ }^{106}$-, und für einige tausend deutsche Templer, die sich in Palästina in britischer Internierung befanden ${ }^{107}$. Diese Germanisierungspläne für die Krim, die einem am grünen Tische entstandenen politischen Interesse Rechnung trugen, ließen eine Volksgruppe außer acht, die wohl noch am ehesten Anrecht auf Kompensation ihrer seit Generationen kultivierten und nun enteigneten Besitztümer und Ländereien in Südrußland hatten: die Deutschen der Krim und der umliegenden Gebiete.

Mit Hitlers Richtlinien zur Rußland-„Politik“ waren die Maßstäbe gesetzt, an denen sich nun alle Ressortchefs zu orientieren hatten. Am 30.10. 1941 rief Rosenberg als Reichsminister für die besetzten Ostgebiete die Vertreter der einschlägigen Ministerien zu einer Planungssitzung in seinem Amtssitz zusammen ${ }^{108}$. Er erinnerte zunächst an das Jahr 385, das Jahr des Hunneneinfalls, das „uns allen wohl in Erinnerung (ist) als ein Jahr" der Wende des europäischen Schicksals, und forderte zu einer Revision dieses Ereignisses auf. Die deutsche Wehrmacht verbinde nun das Baltische und das Schwarze Meer, weite das Reich aus und sichere den Grund für die Eindeutschung und „Schaffung eines Siedlungsraumes für 15-20 Millionen Deutsche“. Das Reichskommissariat Ostland, das die neue Grenze zwischen Slawentum und Germanentum

104 Vgl. Dallin, A., German Rule in Russia. 1941-1945. A Study in Occupation Policies, London 1957, S. 253-57; Luther, M., Die Krim unter deutscher Besatzung, in: Forschungen zur osteuropäischen Geschichte, Band 3 (1956), S.29-98; Ackermann, Himmler, S. 224 ff.; u. a.

${ }_{105}$ Dallin, Rule, S. 255.

106 Vgl. Schriftgutverwaltung des Pers. Stabs des Reichsführers SS, „Gedanken zur Umsiedlung der Südtiroler Volksgruppe in einem geschlossenen Siedlungsgebiet", GR T 175, R 53; GL A. Frauenfeld, „Denkschrift über die Möglichkeit der geschlossenen Ansiedlung der Südtiroler nach der Krim“, ebenda. Vgl. auch: IfZ, MA-247, F 93-110, 16. Mai 1942: Rückberufung Frauenfelds vom Osteinsatz und Vortrag Frauenfelds „Siedlungsmöglichkeiten, Landwirtschaft und Bodenschätze auf der Krim“. Im August 1942 wurde auf Vorschlag des General Thomas (OKW) unter Mitwirkung des Reichsministeriums Ost die endgültige Räumung der Krim von Ukrainern und Russen aus kriegswirtschaftlichen Gründen auf die Zeit nach Kriegsende vertagt; vgl. IfZ MA-144/3, F 5504 ff., Vortragsnotiz OKW/Wehrwi. Amt für Reichsmarschall und Chef OKW (As.), 17.Aug. 1942.

107 Schreiben Himmlers an Frauenfeld, 10.Juli 1942; Frauenfeld an Himmler, 27.Juli 1942, und Himmler an Frauenfeld, 17. August 1942, Nbg. Dok. NO-2417.

108 Niederschrift über die Chefbesprechung am 30.10.1941 im Reichsministerium für die besetzten Ostgebiete über die Landesplanung im Ostraum, BA R 6/102, Ordner 1123-38. 
schaffen werde, solle mit den „kampftüchtigsten Siedlerkräften“ besetzt werden. Das gesamte Ostseegebiet werde eine „Militärkolonie“ gegen den ewig unruhigen Osten. Die Krim, die „früher zum großen Teil deutschen Kolonisten“ gehört habe (ein Drittel des Bodens der Krim gehörte vor dem Ersten Weltkrieg deutschen Grundbesitzern, ein großer Teil davon der geadelten Kolonistenfamilie Falz-Fein), werde „wieder deutsch". Der Führer wolle die Krim zu einer deutschen Riviera und Erholungsstätte für das deutsche Volk machen. Taurien werde deutsch besiedelt werden. Die großen Aufgaben im Osten bestünden nun in „Volkstum und Siedlung“.

Die Frage, wie und mit welchen Kräften die Besiedlung dieser großen Räume durchgeführt werden sollte, konnte, da ein größeres Kontingent von Siedlern nicht zur Verfügung stand, nicht beantwortet werden. Schließlich einigten sich die verschiedenen an der Ostraumplanung beteiligten Stäbe auf einen Vorschlag, der auf Himmler und die Dienststellen im Reichskommissariat für die Festigung deutschen Volkstums zurückging, auf das sog. Kegelbahn-System ${ }^{109}$. Der Plan sah vor, daß die beiden vorrangigen Siedlungs- und Eindeutschungsgebiete, die baltischen Provinzen, und hier vor allem Estland, und die Krim mit Teilen des historischen Taurien durch „Laufbänder" mit dem Deutschen Reich verbunden werden sollten. Im baltischen Raum begannen die Um- und Ansiedlungsstäbe des RFSS RKF deutsche Bauern, die in kleineren deutschen Siedlungen verstreut lebten, zur Zusammensiedlung an Eisenbahnlinien und Autostraßen in west-östlicher Richtung zu zwingen. Diese neuen deutschen Bauernsiedlungen sollten wie an einer Perlenschnur aufgereiht angelegt sein und vor allem strategischen Zwecken dienen. Im Süden Rußlands ist das Kegelbahn-Prinzip nicht über die vorbereitenden Arbeiten hinausgelangt. Auf Hitlers Anordnung sollte vor allem eine Autobahn quer durch die Ukraine bis zur Halbinsel Krim das Laufband bilden, an dessen beiden Seiten die künftigen deutschen Siedlungen aufgereiht werden sollten. Die Siedler wollte man den ehemaligen deutschen Kolonien in der Ukraine entnehmen.

Als eine allgemeine und für alle Ämter bindende Regel der Verwendung der Deutschen aus den verschiedenen Gebieten der Sowjetunion galt die Anweisung, daß „die deutschen Volksgruppen der Schwarzmeergebiete, der Ukraine, Transnistriens und Ostwolhyniens ... auf ihrem alten Siedlungsgebiet ... die Rückkehr ins deutsche Volk erleben " ${ }^{110}$ und als „Eckpfeiler einer künftigen Ostsiedlung in eine neue Ordnung "111 eingefügt werden sollten. Die besonderen Anweisungen zu ihrem „Menscheneinsatz“ sollten vom RFSS RKF ausgehen ${ }^{112}$.

109 Vgl. Kamenetsky, I., Secret Nazi Plans for Eastern Europe. A Study of Lebensraum, New York 1961, S. 59 ff.; Bräutigam, O., Überblick über die besetzten Ostgebiete während des 2. Weltkrieges, Tübingen 1954, S. 80 .

110 Bamm, P., Der große Treck. Rückführung und Rücksiedlung von 350000 Rußlanddeutschen. Schicksale und Erlebnisse, GR T 81, R 294, F $2419153 \mathrm{ff}$.

11 Bamm, Treck, GR T 81, R 294, F $2419162 \mathrm{ff}$.

112 Der Menscheneinsatz. Grundsätze, Anordnungen und Richtlinien. Herausgegeben vom Reichskommissar für die Festigung deutschen Volkstums, Stabshauptamt, Berlin 1940 (und Fortsetzungen). 